\title{
The COVID-19 puzzle: a global nightmare
}

\author{
Hafiza Salaha Mahrosh ${ }^{1} \cdot$ Ghulam Mustafa $^{1}$ (D)
}

Received: 5 June 2020 / Accepted: 2 January 2021 / Published online: 31 January 2021

(c) The Author(s), under exclusive licence to Springer Nature B.V. part of Springer Nature 2021

\begin{abstract}
In December 2019, WHO was informed with several unknown pneumonia cases and later it was found as highly contagious, transmittable and pathogenic viral infection. The novel coronavirus (nCoV-19) was firstly reported from Wuhan city in China. COVID-19 has raised the concern of the world since its emergence from China. The WHO has declared an ongoing COVID-19 outbreak as a pandemic. Till now 6,057,853 confirmed cases with 371,166 deaths have been reported from approximately 213 countries of the world. The aim of this study is to discuss all the aspects related to recently discovered novel coronavirus. The article, therefore, provides a comprehensive study on the genomic, epidemiological, social, clinical and environmental aspects of SARS-CoV-2. SARS-CoV-2 uses human ACE2 receptor as a ligand to bind and transmit its genome just like the SARS$\mathrm{CoV}$. The clinical symptoms of SARS-CoV-2 are very non-specific and include fever, sore throat, wheezing, rales, headache and rhinorrhoea with round-glass pulmonary opacifications shadowing in X-ray. Many antiviral drugs show efficacy but only in mild to moderate infection levels. Though efforts on development of SARS-CoV-2 vaccine have been started earlier as soon as the pandemic was emerged, till date no effective drug or vaccine has been validated with significant efficacy against the disease; therefore, there is a dire need to design effective vaccine against SARS-CoV-2. Multiple vaccine candidates are still in evaluation and exploratory stages on different clinical models with potential results on different animals and human models. mRNA-1273, ChAdOx1, Ad5-nCoV, INO-4800, LVSMENP-DC and pathogen-specific aAPC are the most advanced and potential drug candidates against COVID-19. Recent studies have revealed any attractive vaccine candidates as promising therapeutic agents based on different strategies of vaccines. Here, the rationale of this review was also to provide an overview of the pathogenesis of the virus and summarize the updated potential vaccine candidates against SARS-CoV-2.
\end{abstract}

Keywords SARS-CoV $\cdot$ MERS-CoV $\cdot$ Bat-like $\mathrm{CoV} \cdot n \mathrm{CoV} \cdot$ Pangolin $\mathrm{CoV} \cdot$ In silico analyses

Ghulam Mustafa

gmustafa_uaf@yahoo.com

1 Department of Biochemistry, Government College University, Faisalabad 38000, Pakistan 


\section{Introduction}

The emerging respiratory syndrome (COVID-19) is associated with the novel coronavirus nCoV-19, and it was first discovered in December 2019 in the province Hubei, Wuhan city, China ( $\mathrm{Li}$ et al. 2020a, b). Till date no effective drug or vaccine is available for complete cure of COVID-19, so there is an urgent need to find the vaccine against the nCoV-19 (ul Qamar et al. 2020). Coronaviruses are enveloped, positive single-stranded RNA viruses belong to the subfamily coronavirinae of the Coronaviridae family. Coronavirus from the family of the Coronaviridae consists of four genera which include alpha, beta, gamma and delta coronavirus (Ayittey et al. 2020). The intermediate source for $\mathrm{nCoV}-19$ is still a puzzle which needs to be solved soon in order to find the viral transmission mode. The sequence and polygenetic analysis of nCoV-19 share substantial similarity with SARS-CoV (i.e. bat-like CoV), and therefore, the current outbreak due to novel virus is named as SARS-CoV-2 due to more than $80 \%$ sequence similarity between $\mathrm{nCoV}-19$ and SARS-CoV. The phylogenetic trees of membrane, envelope, nucleocapsid protein and orf $1 \mathrm{a} / \mathrm{b}$ of novel coronavirus closely associated with SARS-CoV, bats, pangolins and civet coronaviruses. The new emerging SARS-CoV-2 is a betacoronavirus closely related to SARS-CoV typically causing severe respiratory illness. Coronaviruses are spherical in shape with diameter of 120-160 nm with outward envelope like projections resembling to a crown and solar corona. Coronaviruses attach to cellular receptors, fused and enter into the cell via endocytosis. The RdRp of viral genome is fully translated and transcribed into viral genome and produced the antigenome. The newly synthesized mRNA and sRNA are transcribed from antigenome. Mature virions egress via exocytosis towards the cellular membrane (Pellett et al. 2014). MERS-CoV, SARS-CoV, Murine coronavirus, Rousettus bat coronavirus HKU9, Hedgehog coronavirus 1 and recently discovered $\mathrm{nCoV}$ (SARS-CoV-2) are all the six betacoronoviruses which cause different diseases in humans and mammals. Furthermore, SARS-CoV, MERS-CoV, HCoV-OC43, HCoV-HKU1 and recently discovered SARS-CoV-2 reported with many infection cases in humans mainly belong to the genus Betacoronovirus (Lim et al. 2016). Evolutionary analysis confirms genetic similarity and linkages of alpha- and betacoronaviruses with the genomes of rodents and bats, and gamma and delta coronaviruses with those of avian species (Shereen et al. 2020).

SARS-CoV-2 is a deadly virus that transmits via respiratory droplets and direct human-to-human contact when an infected person coughs or sneezes. Frequent hand washing or use of disinfectant, social distancing, use of mask and disinfection of things of daily use, surfaces and personal hygiene are some necessary steps which minimize the risk of getting infected (Kaur and Gupta 2020). The symptoms of SARS-COV-2 infection include fever, dry cough, chills, shortness of breath, muscles fatigue, loss of appetite, loss of smell and taste and chest pain. However, recently many cases were reported with mild symptoms or asymptomatic (Shang et al. 2020).

The emergence of CoVs specifically alpha- and betacoronaviruses is known from epidemics caused by SARS-CoV and MERS-CoV in China, South Korea and United Arab Emirates. Previous studies of CoVs revealed their genetic relationship with bats as it was assumed that the gene has jumped and amplified in mammals. Two alpha (i.e. HCoV229E and HKU-NL63) and six coronaviruses (i.e. OC43, SARS-CoV (Severe Acute Respiratory Syndrome Coronavirus), HKU1, 229E, NL63 and MERS-CoV (Middle East Respiratory Syndrome Coronavirus)) have been reported as well-known causes of great epidemics in the past (Naji 2019).

Many intermediate reservoirs of SARS-CoV and MERS-CoV have been found from detailed literature survey and experimental study (Fig. 1). It is necessary to reveal 


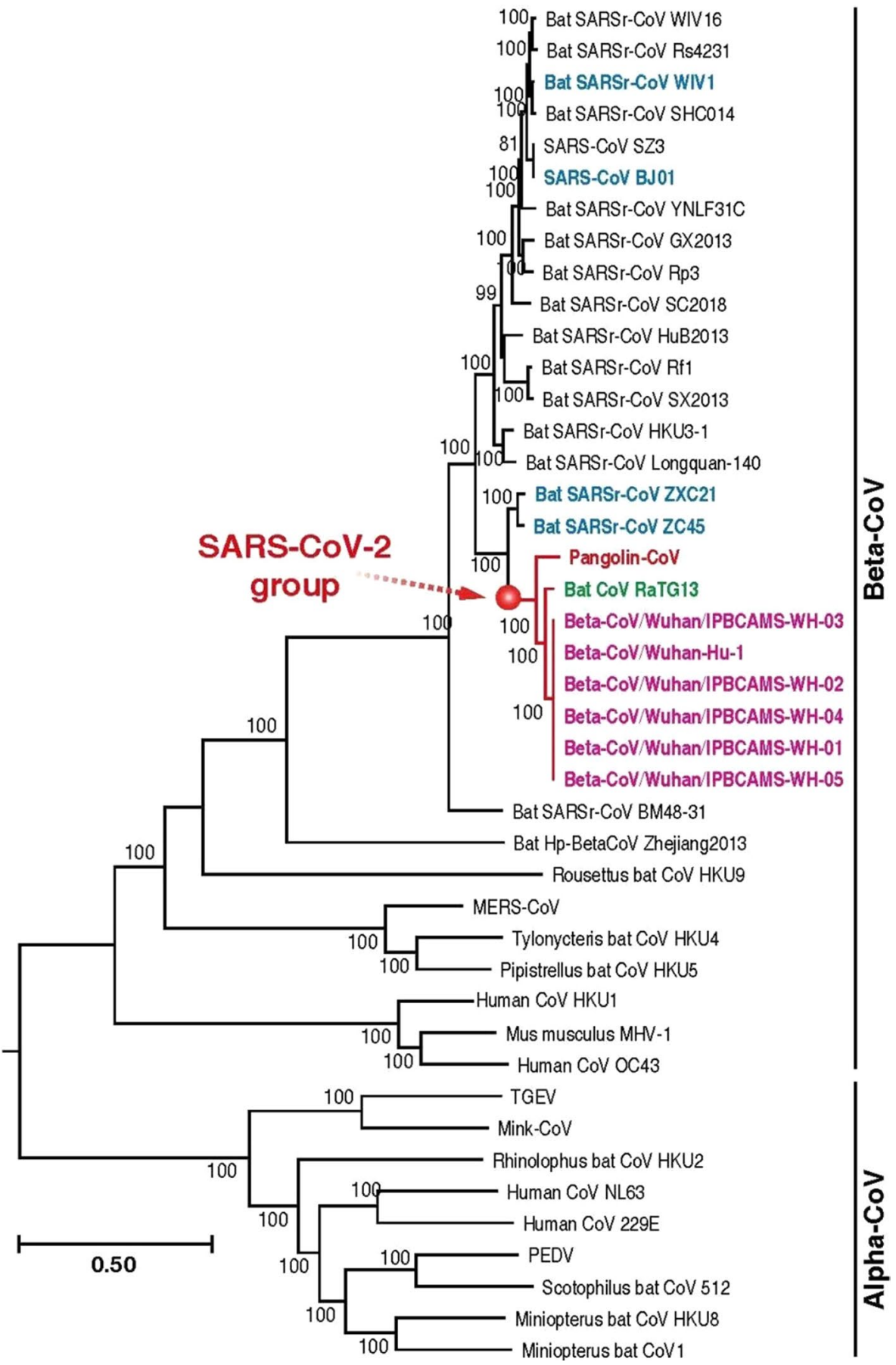

Fig. 1 Whole genome-based phylogenetic relationships of CoVs (Source: Zhang et al. 2020) 
the intermediate host of $\mathrm{nCoV}-19$ in order to understand its transference route. It was assumed from the genetic comparison that pangolin and RaTG13 bat-like CoV might be the intermediate host of SARS-CoV-2. Lu et al. (2019) isolated the sample from pangolin lungs and detected SARS-CoV like CoVs. Besides RaTG13 CoV, the spike protein subunit S1 of SARS-CoV-2 was more closely associated and resembled with pangolin $\mathrm{CoV}$. Spike protein interaction mediated amino acids are also consistent among SARSCoV-2 and pangolin CoV (Zhang et al. 2020).

Based on genetic alignment, the genome of pangolin CoV shows $91.2 \%$ identity with nCoV-19 and 90.55\% with RaTG13-Bat-CoV (Kakodkar et al. 2020). The pangolin $\mathrm{CoV}$ genome comprises six open reading frames and four genes identical to CoVs. The genetic analysis has revealed high nucleotide and amino acid similarity of pangolin $\mathrm{CoV}$ with other coronaviruses and specifically with novel coronavirus (nCoV-19). Relying on the phylogenetic information, SARS-CoV-2, pangolin CoV and other CoVs are clustered in the same clade based on their nucleotide sequences, RNA-dependent polymerase, $\mathrm{S}$ and $\mathrm{M}$ proteins encoded genes and ORF1a and ORF1b genes. Therefore, all the genomic drafts pointed that pangolin could be the intermediate reservoir of the SARSCoV-2 (Zhou et al. 2020).

The genetic analysis of SARS-CoV and SARS-CoV-2 reveals that both share $79 \%$ similarity with 380 amino acid substitutions between the non-structural protein (NSP) genome. Among these amino acid substitutions, 27 have been found in spike protein, 102 in NSP3 and 61 amino acid substitutions in NSP2 (Wu et al. 2020). The ORF1ab of SARS-CoV-2 encodes 16 NSPs of viral genome (Yoshimoto 2020). These non-structural proteins of SARS-CoV-2 are involved in different functions such as replication, rearrangement of membrane, capping, tailing, RNA unwinding, methylation and cleavage of host mRNA (da Silva et al. 2020). The 3' end of SARS-CoV-2 genome encodes four structural proteins which are spike protein $(S)$, membrane protein $(M)$, envelope protein $(E)$ and nucleocapsid protein $(N)$, and all these proteins play vital roles in the viral life cycle. Among four structural proteins, spike protein being a large and versatile protein plays an important role in attachment, fusion and entry of virus into the host cell.

The spike protein consists of two functional subunits (i.e. S1 and S2) which contain domains and motifs of viral genome. $S 1$ and $S 2$ spike protein subunits have indicated the same functions in pangolin coronavirus and novel coronavirus (nCoV-19). $S 1$ subunit of spike protein has two receptor binding domains (RBD) responsible for recognising and binding with receptor ACE2 in humans and one $N$-terminal domain while $S 2$ subunit contains receptor binding motifs (RBM) (Jiang et al. 2020a, b). The detailed analysis of RBD region of $S 1$ subunit of SARS-CoV-2 has showed conserved amino acids sequence with change at one position only when compared to pangolin $\mathrm{CoV}$ and 17 mutational changes when compared to RaTG13-Bat-CoV. A deep genetic level study is still needed to check the binding affinity of both CoVs with the host ACE2 receptor to ensure whether pangolin CoV or RaTG13 are pathogenic intermediate agents for SARS-CoV-2 infection (Zhou et al. 2020). The intermediate hosts and targets of different CoVs are given in Table 1.

The envelope protein forms viroporins (E-channels) which are involved in the replication, assembly, release and pathogenicity of SARS-CoV-2. The E-channel is comprised of transmembrane domain (TMD) responsible for membrane linkage in the host cell. Mainly the SARS-CoVs have 3 ion channels as E, 8a and 3a. The 8a and E-channels contain post synaptic density protein (PDZ), disc large tumour suppressor and domain binding motif (PBM) that cause the overexpression of inflammatory cytokines which result in cytokine storm (Castaño-Rodriguez et al. 2018). 
Table 1 Intermediate hosts and main targets of different CoVs

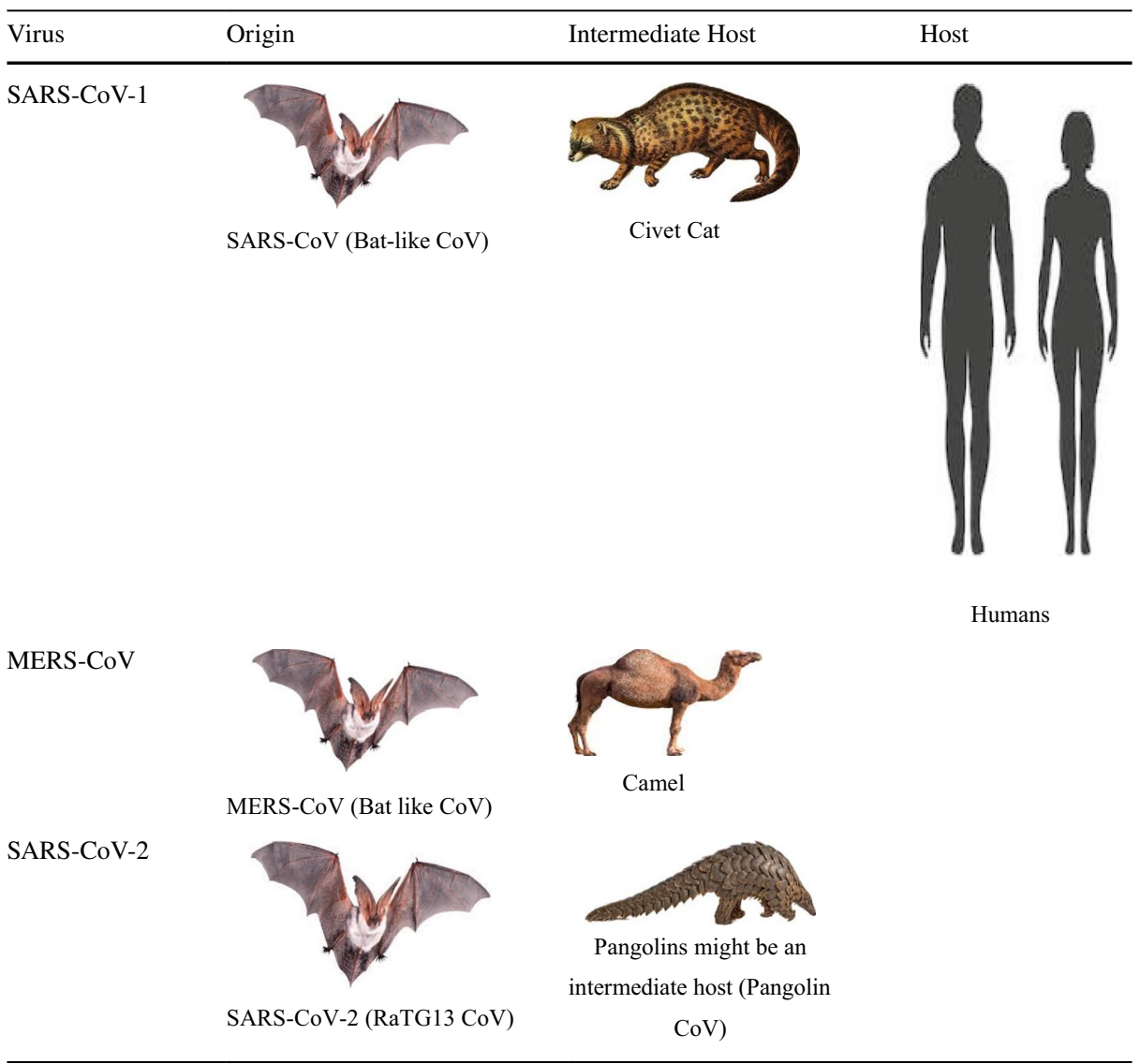

Membrane protein is regarded as a crucial planner in the assembly of CoV genome, induction of apoptosis in host cell, and it is mostly expressed in virus particles. Membrane protein interacts with other structural proteins essentially to maintain the morphogenesis and assembly of SARS-CoV-2 genome (Kaur and Gupta 2020). The nucleocapsid protein is antagonist to antiviral RNAi by binding with M protein the $\mathrm{N}$ protein stabilizes the RNA complex and internal core of the viral genome (Yoshimoto 2020).

The transmission rate of SARS-CoV-2 infection is still a puzzle as some people do not transmit the infection yet some cause superspreading. The unknown amount of replication of the competent virus is responsible for the transmission of viral infection (Klompas et al. 2020). The experimental study on the culture of SARS-CoV-2 explains the heat sensitivity, viral load in patients and presence of virus on different surfaces in different environmental conditions. SARS-CoV-2 spike protein binds to the angiotensin-converting enzyme 2 (ACE2) of host cell. Viral load is high in early periods of infection in upper respiratory tract, but as time passes the viral load gradually decreases indicating that the upper respiratory tract is the critical point of viral replication (Wölfel et al. 2020).

Immunotherapy involves the triggering of immune system to evoke the immunity, regarded as effective method for treatment of many infections and cancers. In 
SARS-CoV-2 the primary goal is to produce neutralizing antibodies against spike protein to target the central organizer of the virus. The database of isolated genome of SARS-CoV-2 from different countries indicated the polymorphism mainly in $S$ protein and other important proteins concerning vaccine development. Furthermore, the clinical study indicated limited or no cross neutralization between SARS-CoV and SARSCoV-2 sera indicated that the recovery cannot be linked to other infections. About 135 vaccine candidates are in clinical or investigational stages for vaccine development. The latest candidates include Ad5-nCoV by CanSino Biologicals, ChAdOx1 by University of Oxford, mRNA-1273 by Moderna, INO-4800 by Inovio, Inc. and pathogen-specific aAPC by Shenzhen Geno-Immune Medical Institute which have been successfully entered into the Phases II/III of vaccine development (Kaur and Gupta 2020).

Here, the purpose of this article is to review the current understanding of SARS-CoV-2 such as its genomic, epidemiological and clinical features, as well as its unique contagious characteristics differing from those of SARS-CoV and MERS-CoV, providing the essential information for adjusting our responses against SARS-CoV-2 pandemic. The rationale of this review was to gather all the ongoing research and vaccine development programmes to facilitate the readers and researchers about the latest situation of ongoing pandemic.

\section{Epidemiology}

On 31 December 2019 WHO was informed with some unknown respiratory pneumonia cases. Total 43 different cases were reported from different regions among them 6 with more critical conditions. The case studies on COVID-19 suggest the relationship of affected people with seafood market in Wuhan, and second, the human-to-human interaction frequency increases with direct human contact. People with low immunity, higher age and clinical history are at high risk to this viral infection. It has been reported that the outbreak caused by nCoV-19 that occurred from seafood markets in Wuhan from wild animals. A key point in analysis is that both the COVID-19 and SARS-CoV in 2002 erupted in winter season because of the exposure of some animals being sold in the markets. Some early analyses held environmental specimens responsible for the outbreak but the WHO report shows that there has been no evidence for the origin of the virus in any animal ( $\mathrm{Ji}$ et al. 2020).

Some researchers showed that snakes are the reservoir of the virus but it was dismissed by scientists. A lot of scientists stated that not only snakes but a wide range of animals carry the virus. Researchers are still working to find a definite intermediate reservoir (Shereen et al. 2020). The initial cases were highly related to those who visited the wet market but surprisingly a lot of people who have not visited the markets including a large number of health workers were affected, and this shows the likeliness of spread of virus through aerosols, large respiratory droplets and by direct human-tohuman contact.

As of 12 February 2020, the WHO reported 45,171 cases and 1115 deaths worldwide due to COVID-19 among them $99 \%$ of infections and $99.9 \%$ of deaths reported from China. To tackle with infection, precautionary measures and protocols are launched to evade further spread of COVID-19. The report by WHO shows that the virus is spreading rapidly and many scientists are working on drugs to fight the virus (Kannan et al. 2020). The genomic and evolutionary analyses have revealed sequence similarity between the novel coronavirus-19 with betacoronavirus specifically with SARS-like CoV (Chan et al. 
2020). COVID-19 with zoonotic origin mainly caused by the SARS-CoV-2, and there is $80 \%$ sequence similarity between SARS-CoV-2 and SARS-CoV (Bat virus).

The onset of the viral infection appears after 7-14 incubation period, but this varies from person to person due to state of person's immune system and clinical history. The chest computed tomography (CT) of infected person shows the ground glass pulmonary opacification (GGO) in sub-plural region. From the comparison of infections, it seems that pulmonary soft tissues density decreases in both nCoV-19 and SARS-CoV. Detailed study indicates that COVID-19 mainly targets the lower air passage way more specifically cause the inflammation and hypoxemia. The morbidity and mortality rate of this virus increases due to high capability transmission (Zhao et al. 2020). According to WHO, the COVID-19 confirmed cases are recorded as 42, 512, 186 with 1,147, 301 deaths cases worldwide (Oct 26, 2020). WHO-published guidelines mainly focused on core protocols against the COVID-19 and health emergencies. Daily-based reports have been published officially in order to spread awareness about COVID-19 (Figs. 2, 3).
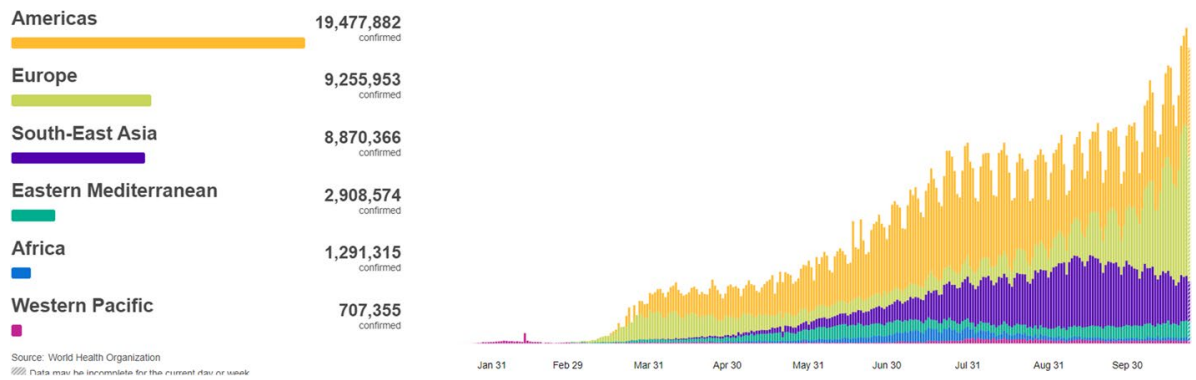

Fig. 2 Comparison of reported cases from different regions till 26 October 2020 (https://covid19.who.int/)

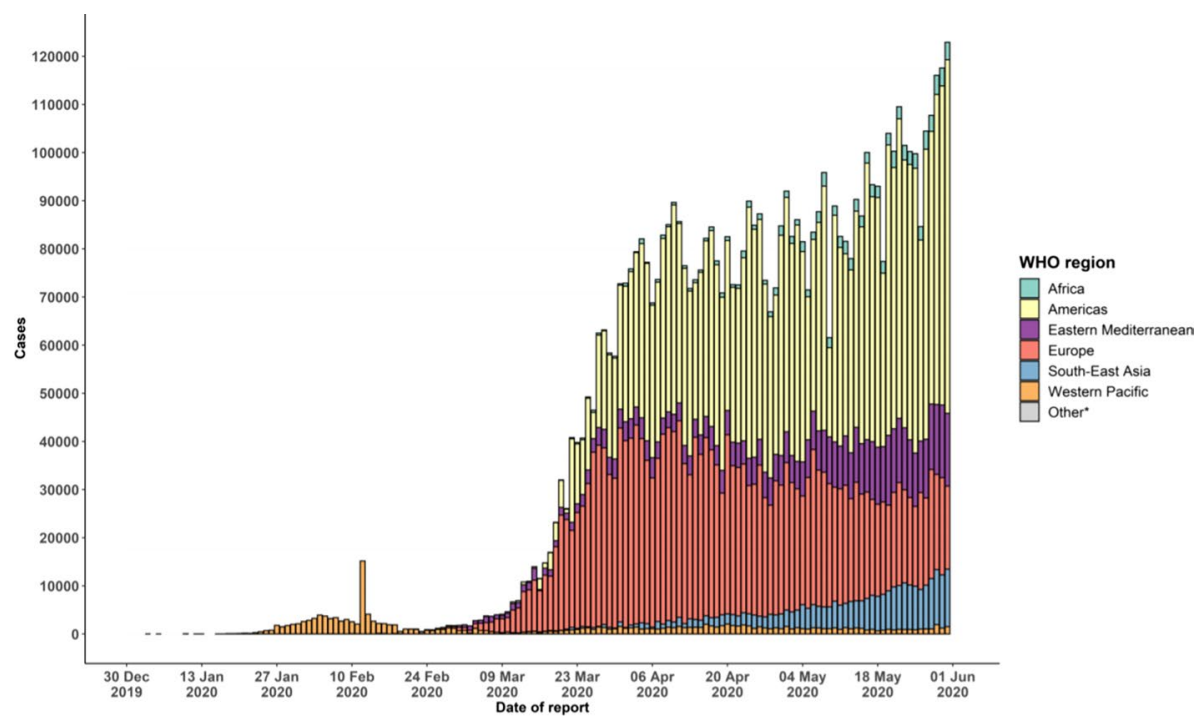

Fig. 3 COVID-19 confirmed cases Epidemic Curve, report date and WHO region through 1 June 2020 (World Health Organization (2020a, b). Coronavirus disease 2019 (COVID-19): situation report) 


\section{Pattern of infection}

World health organization characterized the $n \mathrm{CoV}-19$ as a beta-CoV2B group. On the basis of genome pattern and sequence similarity, nCoV-19 shows a distinct relationship with MERS-COV (i.e. about 50\%) but a close relationship with SARS-CoV (i.e. about $80-86 \%$ ). This is the 7th member of corona family that causes such chaos. The binding pattern of viral protein with human ACE2 receptor and similarity in RBD domain amino acids pointed towards the relationship between the $\mathrm{nCoV}-19$ with CoVs specifically with betacoronaviruses. As far as about current situation, there is no vaccine till now for the control of viral load although some antivirals and interferon alpha nebulization are still used to decrease the viral replication (Hamid et al. 2020).

All coronaviruses used specific ORF1a gene that codes replication proteins, nucleocapsid protein and spike protein (Van Boheemen et al. 2012). SARS-CoV and MERS-CoV recognize exopeptidases mainly rely on cellular peptidase that split Spike protein which enables to penetrate into host cell. SARS-CoV and SARS-CoV-2 recognize human ACE2 (angiotensin-converting enzyme 2 receptor) as key receptor while the MERS-CoV recognize dipeptidyl peptidase 4 (DPP4) as receptor (Shereen et al. 2020). The structure of SARS-CoV-2 is very preserved in order to express different types of polyprotein, replication proteins, spike protein, nucleocapsid and membrane protein, RNA polymerase helicase, papain protease and chymotrypsin-like protease (Bertram et al. 2011) and shown in Fig. 4. The spike protein is the major associated viral protein splits into $S 1 \mathrm{~ns} S 2$ subunits with loosely attached RBD domains to mediate the viral entry and replication in host cell (Shereen et al. 2020).

The infection pattern follows the binding and fusion of receptor binding domains of viral spike protein with human cellular receptor angiotensin-converting enzyme 2 receptor (ACE2) on pneumocyte type 2 via endocytosis, the entry and binding pattern with human cellular receptor of $\mathrm{nCoV}-19$ matched with the SAR-CoV so this indicates the likelihood between the entry of both viruses into the host (Hamid et al. 2020). The activation of spike protein is a necessary process in order to bind the virus receptor with its ligand in host cell (ACE2), so receptor protein primed with the TMPRSS2 protease just like the SARS-CoV (Fig. 5).

ACE2 (angiotensin-converting enzyme 2 receptor) from family of dipeptidylcarboxy dipeptidase is human outer membrane enzymes present at the surface of cells membrane provide binding site for SARS-CoV-2 and SARS-CoV invasion. After activation by protease virus successfully enters into host cells prepare its genome to replicate. Both

Fig. 4 Binding domains and fusion mechanism of Human coronaviruses (Jiang et al. 2020a, b)

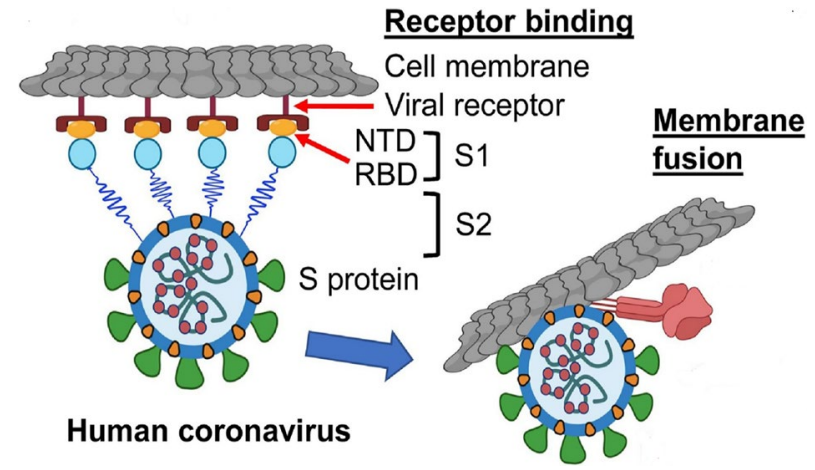

Springer 
Fig. 5 Attachment and activation of spike protein (Hoffmann et al. 2020)

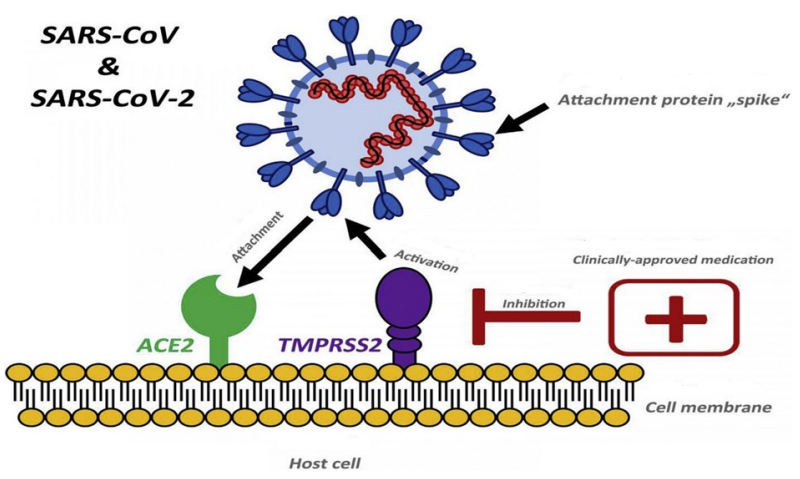

continuous and discontinuous RNA synthesis occurred at cytoplasmic membrane of viral encoded by $20-\mathrm{kb}$ replicase gene and mediated by RNA polymerase, RNA helicase and other proteases. The exceptional case with novel coronavirus(nCoV-19) is the presence of variety of RNA processing enzymes including 3'-to-5' exoribonuclease, nucleoside 2-O-methyltransferase, ADP-Ribose-1-phosphatase with cyclic nucleotide phosphodiesterase properties that were absent in other RNA viruses. After the assembly of these proteins, the RNA matured as genome particle budding off from the internal membrane (Hoffmann et al. 2020). RNA of virus acts as the (PAMP) pathogen associated molecular pattern by toll-like receptor leads to the migration of neutrophil due to chemokine surge and results the destruction of alveolar duct walls.

From the previous studies, coronaviruses were not considered as highly pathogenic until the SARS outbreak in 2002-2003 in China and in 2012 MERS in Saudi Arabia, Korea and UAE, but this nCoV-19 is a highly pathogenic one among all previous viral infections in human history (Zhao et al. 2020) (Fig. 6).

\section{Methodology}

All the aspects regarding SARS-CoV-2 have been discussed in this article after careful literature review. The clinical manifestations of SARS-CoV-2 classify severity of presentation range from mild to severe outcomes. The symptoms of the COVID-19 appear usually within 2-14 days after the initial exposure to virus. The transmission rate of viral load varies from person to person as many people transmit virus without any signs of illness. The SARS-CoV-2-infected patients show symptoms of dry cough, sore throat, shortness of breath, dyspnoea, fatigue, fever, chills, muscle pain and weakness with nasal stuffiness and congestion sometimes or other respiratory tract infections including runny nose. Pyrexia is still a representative symptom, despite atypical symptoms of SARS-CoV-2 (Lam et al. 2020). Positive signs are not shown by some patients with mild symptoms whereas patients in severe conditions show abnormal crackles, shortness of breath with weakened sounds, increased or decreased vocal tremor with irregular rhythms in muscle movement.

The testing of COVID-19 is associated with the likelihood of assessment of disease and epidemiological factors. Testing of COVID-19 includes authorized home testing kits approved by Food and Drug Administration (FDA). The first step is to call the doctor if you are suspected about your condition. Upon the instructions of doctor or health care department, collect the nasal sample using cotton swab and mail the sample to the designated 


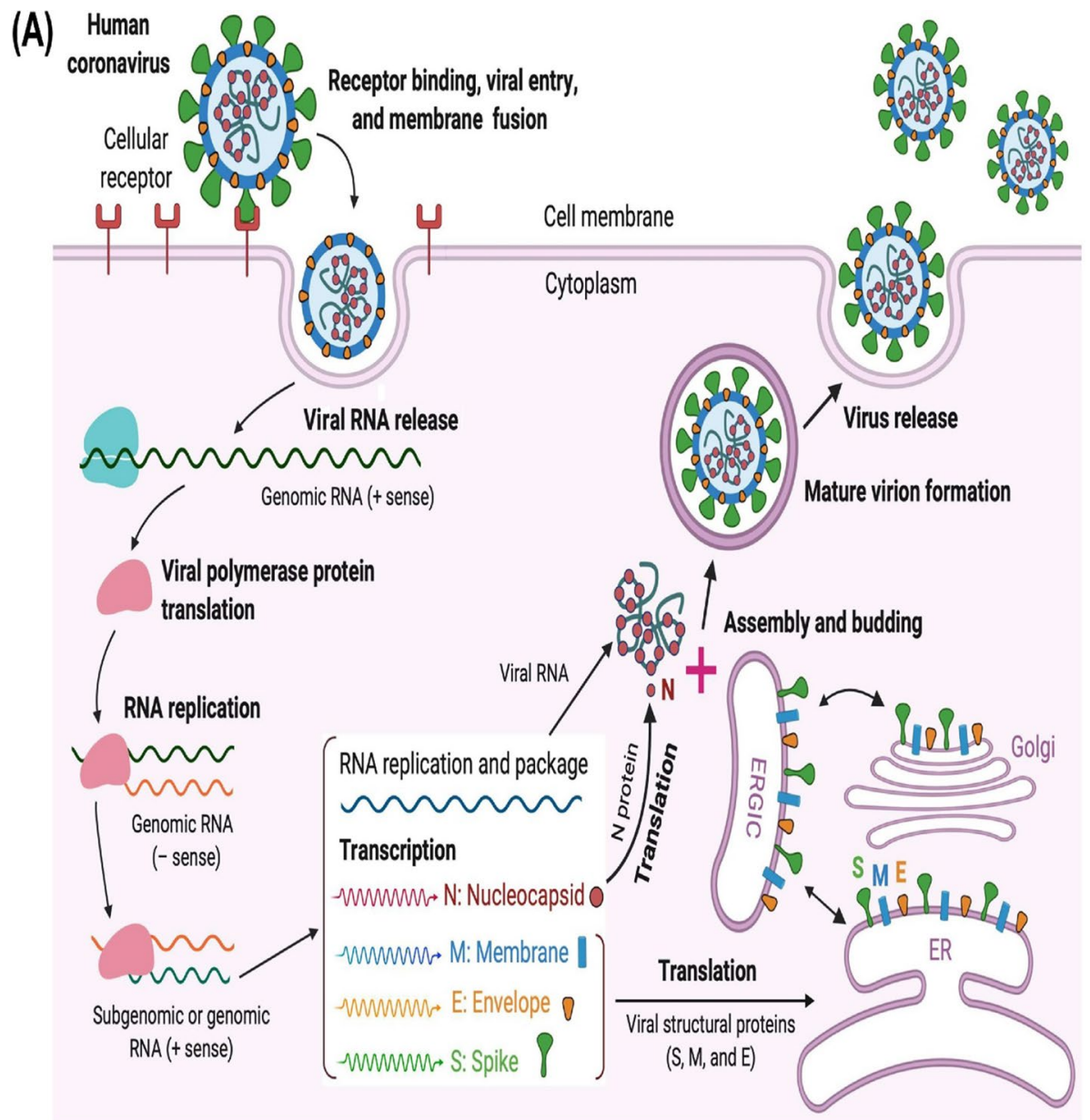

Fig. 6 SARS-CoV-2 life cycle and full mechanism into host cell (Source: Jiang et al. 2020a, b)

laboratory. In other case, if someone has no approach to use home testing kits then he/ she must visit the nearest hospital or collection centre under precautionary measures. The training of staff and handling of sample for collection of sample, storage and transportation is critical and important points. All the collected samples should be regarded as highly infectious. Specimens should be transported at $2-8{ }^{\circ} \mathrm{C}$ on dry ice and stored at $-70{ }^{\circ} \mathrm{C}$ in case of delay. The initial stage is following screening protocols after the onset of the infection. In COVID-19 crowded area single algorithmic screening should be preferred and considered sufficient. Serological testing assists the investigational study on the rate of extent of ongoing outbreak (World Health Organization 2020b) (Table 2).

The infectious agent of SARS-CoV-2 is detected by the presence of RNA virus by molecular testing mainly RT-PCR. The infectious pattern and transmission mode depends on whether the virus is replication competent lentiviruses (RCL) or the patient is symptomatic and if the environment behaviour is associated with the patient. Usually from 4-15 days after the onset of infection, the body starts to produce neutralizing antibodies that minimize the risk of viral transmission (WHO 2020b). 
Table 2 Specimen collection and storage (Druce et al. 2012; WHO 2018; WHO 2020c)

\begin{tabular}{llll}
\hline $\mathrm{Sr} \#$ & Specimen type & $\begin{array}{l}\text { Material for col- } \\
\text { lection }\end{array}$ & $\begin{array}{l}\text { Temperature until testing } \\
\text { in laboratory }\end{array}$ \\
\hline 1 & Bronchoalveolar washing & Sterile container & $2-8{ }^{\circ} \mathrm{C}$ \\
2 & $\begin{array}{c}\text { Nasopharyngeal and oro- } \\
\text { pharyngeal swab }\end{array}$ & $\begin{array}{l}\text { Dacron or polyester } \\
\text { flocked swabs }\end{array}$ & $2-8{ }^{\circ} \mathrm{C}$ \\
3 & Tissue from autopsy & $\begin{array}{c}\text { Sterile container } \\
\text { with saline }\end{array}$ & $2-8{ }^{\circ} \mathrm{C}$ \\
4 & Sputum & Sterile container & $2-8{ }^{\circ} \mathrm{C}$ \\
5 & Blood & Blood container & $2-8{ }^{\circ} \mathrm{C}$ \\
\hline
\end{tabular}

SARS-CoV 2 is different from other known pneumonia-causing viruses, such as parainfluenza virus, human orthopneumovirus, influenza viruses, Chlamydia pneumonia, adenovirus, dermatomyositis, mycoplasma pneumonia and bacterial pneumonia (Jin et al. 2020). Isolation of viral genome is golden key to identifying the genome of viruses from specimens in a timely manner (Yu et al. 2020). Real-time RT-PCR method has shown the full genomic sequence of SARS-CoV-2, and the samples can be collected from nose, back of throat, sputum, lower (i.e. endotracheal aspirate, expectorated sputum, bronchoalveolar washing) or upper (i.e. oropharyngeal and nasopharyngeal) respiratory tract of patients who are suspects of SARS-CoV-2. Leukocytes count is another method to diagnose disease in early stage, the number of leukocytes decreases than the normal number of leukocytes (Wu et al. 2020).

In early pneumonia stage, images of chest show interstitial changes with multiple tiny patchy shadows in peripheral region of lungs (Fuk-Woo et al. 2020). More critical case study has shown lungs consolidation, bilateral multiple ground glass opacifications and pleural effusion. Computational tomography scan shows more clear pulmonary lesions as compared to X-rays which show ground glass opacities, bronchiectasis, bilateral pleural lesions and lung consolidation. Multiple lesions are present in both lungs in children with severe infections. Moreover, study showed that 41 patients with confirmed nCoV-19 had bilateral lung involvement on chest radiography. All in all, the study findings are similar to SARS (Ooi et al. 2004) and MERS (Das et al. 2015) which is not shocking because all are coronaviruses. The factors that intervene image finding include immunity status, patient's age, underlying diseases, drug intervention and condition of disease at scanning (Huang et al. 2020).

\section{Precautionary measures}

Continuous hand wash for 20 seconds, $60 \%$ alcoholic content containing sanitizer or hand wash is recommended for use after visiting public places. It is necessary to avoid the touching of facial T-zone (ear, nose and mouth) in order to block the accessing points for viral entry into the host. Unnecessary traveling to pandemic areas is strictly prohibited. Daily base sterilization is also recommended in order to prevent the viral attack (Kakodkar et al. 2020). Personal protective equipment includes gloves, N95 masks, eye shields, full sleeve double gowns and surgical masks are necessary for every health care professional. N95 masks block $95 \%$ of aerosols to enter into mask so it is 
exclusive for person to wear while performing the procedure that have high risk of aerosols exposure include tracheostomy, bronchoscopy, cardiopulmonary resuscitation (CPR) and tracheal intubation on COVID-19 patient. Aged persons need to quarantine themselves to decrease the like hood of viral attack.

On the onset of any symptom, the person immediately self-quarantine himself for 14 days and contact with online helpline with healthcare professionals. The self-isolation must be for humans as well as from pets as there are recorded cases for human-dog viral transmission. As there is no current vaccine, precautionary measures are necessary in order to avoid SARS-CoV-2 infection (Kakodkar et al. 2020).

\section{Signs and symptoms}

Respiratory infection with fever and dry cough is most prominent in COVID-19 patients. Some other distinct features like nausea, vomiting, diarrhoea, and gastrointestinal infections appeared in significant proportion of patients. Radiological and computational tomography of COVID-19 patients showed the Lobular or bilateral carcinoma and ground glass pulmonary opacities. Abnormal levels of Erythrocyte sedimentation rate (ESR) and plasma C-reactive protein (CRP) with low platelet count were persistently reported from 63\% subjects (Lupia et al. 2020). Furthermore, elevated levels of plasma interleukins, chemokines, pyrogenic cytokines, creatinine and plasma blood urea nitrogen were also documented from the critical patients of COVID-19 (Huang, et al. 2020).A case study on Non-COVID-19 and COVID -19 patients pointed towards the elevated levels of Lactate dehydrogenase (LDH), Alanine aminotransferase (ALT), Aspartate aminotransferase (AST), and $\alpha$-hydroxybutyric dehydrogenase $(\alpha-\mathrm{HBDH})$ in affected patients (Zhao et al. 2020). Depending on the clinical features and onset of symptoms the patients are divided into four subcategories as mild, moderate, severe and critical COVID-19 (Singh et al. 2020).

\section{COVID-19 consequences}

China is extremely important to the global economy. China has already fought with many epidemics include outbreak of SARS in 2002. Moreover, the gross domestic production of China was $4 \%$ of the total but it is now $17 \%$. COVID-19 has strongly seized the economic war with US, which resulted in hitting the national growth a 30 year low in 2019. Provinces which provided $90 \%$ of export are now shutdown. The pandemic of COVID-19 cause to shut down many important business-like productions of crude oil. Furthermore, the difference between SARS and COVID-19 are complicated put the China and many developed countries in a difficult state. Global dependence on them is a comparatively new phenomenon because there is little evidence in history about such supply chains (Sohrabi et al. 2020). 

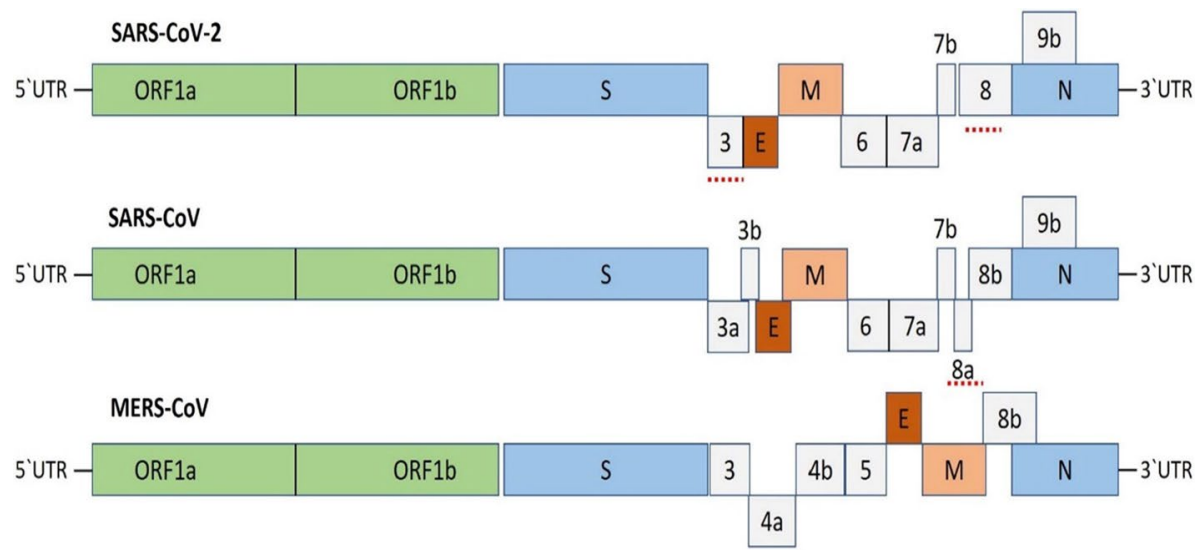

Fig. 7 Genomic organization of betacoronaviruses. Genome comprises 5'-untranslated region, open reading frames (ORF1a, ORF1b), spike protein $(S)$, envelope protein $(E)$, membrane protein $(M)$, nucleocapsid protein $(N)$, accessory proteins and $3^{\prime}$-untranslated region. The key mutations between SARS-CoV and SARSCoV-2 have been underlined with red dots (Source: Shereen et al. 2020)

\section{Genetic variation}

The genomic analysis of SARS-CoV-2 has revealed over $80 \%$ identity with SARS-CoV (Wu et al. 2020) that include main genes which code for structural and non-structural proteins (Fig. 7). The structural protein genes mainly code four types of structural proteins (i.e. spike (S) protein, envelope (E) protein, membrane $(\mathrm{M})$ protein and nucleocapsid $(\mathrm{N})$ protein). The gene of largest ORF1ab of SARS-CoV-2 encodes 16nsps and Orf1ab polyprotein protein and the gene of ORF1a encodes for protein pp1a and 10nsps. The comparative structural analysis of SARS-CoV and SARS-CoV-2 represents notable mutations including the deletion of $8 \mathrm{a}$ protein and variation in $8 \mathrm{~b}$ and $3 \mathrm{c}$ proteins amino acids of SARS-CoV-2 (Shereen et al. 2020). The spike protein of SARS-CoV-2 is a combination of bat coronavirus and unknown betacoronovirus as a result of homologous recombination ( $\mathrm{Li}$ et al. 2020a, b). Fluorescence study has revealed that the virus also uses ACE2 receptor of host cell for fusion via spike glycoprotein just like the SARS-CoV (Xu et al. 2020). N501T mutational change in SARS-CoV-2 spike protein intensifies binding affinity and entry of virus into the cell (Wan et al. 2020).

\section{Genome structure and life cycle}

Coronaviruses have the biggest genomes of about 24.5-37.17 kb and RNA viruses with 33 to $44 \%$ GC content. Coronaviruses are spherical positive single-stranded RNA particles packed with enveloped protein and associated with nucleocapsid protein encapsulated in matrix protein with outer most spikes protein protecting layer around the envelope. Coronaviruses typically comprise small open reading frames ORF1ab, four structural proteins as $S, M, E$, and $N$ protein in distinctive pattern from 5 to 3 end (Hoffmann et al. 2020). A schematic representation of SARS-CoV is shown in Fig. 8.

At least 6 ORFs are present in typical CoVs (expect gamma coronavirus ORF1a and ORF1b), comprised of frameshift encodes for two polypeptides PP1a and PP1ab processed 
Fig. 8 Schematic diagram of SARS-CoV (Source: Ksiazek et al. 2003)

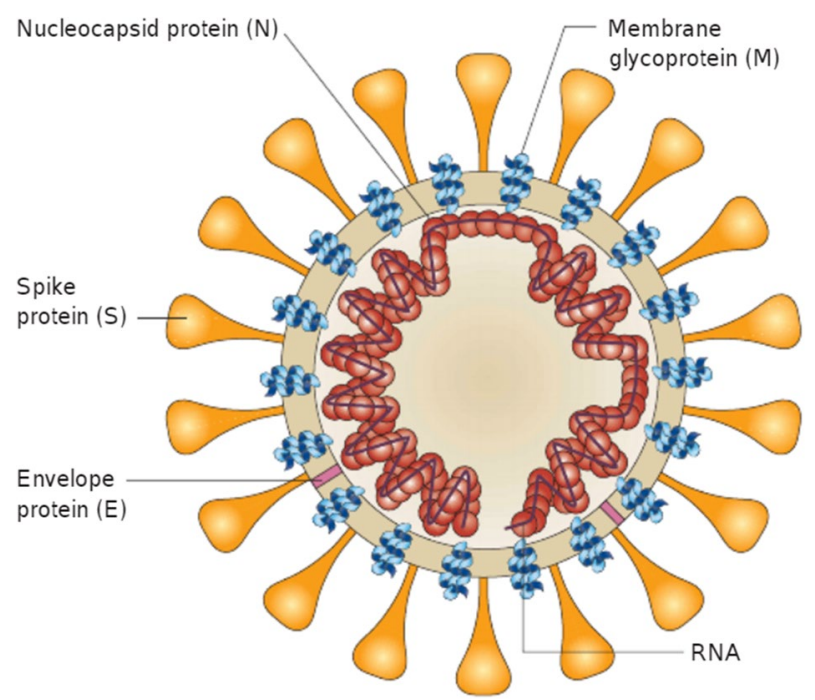

by viral replication manner encoded main protease (M-Pro), chymotrypsin-like protease (3CLPRO) and papain-like protease (PL-pro) into $16 \mathrm{nsps}$.

All the proteins are encoded by viral sgRNA and mature proteins are responsible to reveal functioning, maintenance and replication. The abundant protein is the membrane protein which is glycoprotein in nature and has occupied three parts of lipid layers with $\mathrm{NH}^{2+}$ terminal outside and $-\mathrm{COOH}$ terminal inside (towards the cytoplasm). Secondly, the spike protein which is the main protein mediates virus for anchoring into the host cells receptor. Envelope protein is responsible for the formation and composition of viral membrane. Nuclear capsid protein forms a capsid around the viral genome and enhances the replication (van Boheemen et al. 2012).

In the genetic comparison of nCoV-19, SARS-CoV, and MERS-CoV, nCoV-19 showed differences in its sequence when compared with MERS-CoV. SARS-CoV-2 amino acids pattern in the region of lab-polyprotein and $S$ protein or glycoprotein differs a lot from other coronaviruses. What helps the virus entry into cells is the $\mathrm{S}$ protein with two subunits, one for direct binding of virus to the host receptor. The nCoV-19 spike protein RBD domain has significant homology with SARS-CoV. Although some of the receptor binding residues are slightly different, all in the receptors which were not identical do not change the structural conformation. As many coronaviruses including SARS-CoV enter into human cells via ACE2 receptors, studies show that for nCoV-19 human receptor can be angiotensin-converting-enzyme 2 (ACE2) (Hoffmann et al. 2020). Pathogenicity and virulence of all known coronaviruses are discussed in Table 3.

\section{COVID-19 and common flu}

There occurred four different types of influenza viruses A, B C and D, A and B type are major causative agents for the flu. Influenza virus from Orthomyxovirus family and $\mathrm{nCoV}$ 19 matched in symptoms as both caused respiratory disorder, transmit through contact but 
Table 3 Comparison of virulence of different coronaviruses (Lupia et al. 2020)

\begin{tabular}{llll}
\hline Features & SARS-CoV & MERS-CoV & SARS-CoV-2 \\
\hline $\begin{array}{lll}\text { Natural reservoir } \\
\text { Origin }\end{array}$ & Bat & Bat & Bats \\
& Guangdong Province, & Saudi Arabia, United & Wuhan, China \\
China & Arab Emirates & \\
Number of cases & $2-7$ days & 5 days & $2-14$ days \\
& $8098(2002-2003)$ & $2254(2012-2013)$ & $\begin{array}{l}6,057,853 \text { con- } \\
\text { firmed cases of } \\
\text { COVID-19 till 1st }\end{array}$ \\
& & & June \\
Severity of disease & Moderate to severe & High & High \\
Fatality rate & $9.6 \%$ & $34.4 \%$ & $3.5 \%$ \\
\hline
\end{tabular}

Table 4 Incubation summary of CoVs and Influenza Viruses (Kakodkar et al. 2020)

\begin{tabular}{llll}
\hline Virus family & Virus & Disease & Incubation period \\
\hline Coronavirus & SARS-CoV-1 & SARS (Severe Acute Respiratory Syndrome) & 5 days \\
& MERS-CoV & MERS (Middle East Respiratory Syndrome) & 2-7 days \\
& SARS-CoV-2 & COVID-19 (coronavirus disease 2019) & 2-14 days \\
$\begin{array}{c}\text { Orthomyxo- } \\
\text { virus }\end{array}$ & Influenza A & Seasonal flu & 2 days \\
& H1N1 Influenza A & Swine Flu & $1-4$ days \\
\hline
\end{tabular}

with different levels of pathogenicity and vary from asymptomatic to pneumonia severity. Nasal congestion, rhinorrhoea and wheezing are common in both viruses. The severity and transmission of infection are determined by Basic Reproduction Number $\left(\mathrm{R}_{\mathrm{o}}\right)$ which is $\sim 1.3$ for influenza virus and $\sim 2.3$ for SARS-CoV-2 indicates that SARS-CoV-2 is 1.8fold stronger and more transmitted from effected person. The time period from pathogen exposure to clinical manifestation determined by incubation period and it varies in COVID-19 persons. Table 4 explains the incubation period and comparison with different other CoVs and influenza viruses (Kakodkar et al. 2020).

\section{Transmission and spread}

Not a lot of studies out there show pathophysiological features of COVID-19 infection, and the mechanism of its transmission is still unclear. The mostly observed cases indicate transmission of coronaviruses through aerosols via direct human-human contact. Normally, respiratory viruses are more dreadful when the patient is symptomatic. But in case of nCoV19 the transmission of infection occurred between the incubation period from 2-14 days when the suspect is asymptomatic (Sohrabi et al. 2020). As of 3 March 2020, 90,870 cases of COVID-19 have been confirmed, 80,304 from China, 67,217 were confirmed in Hubei province while remaining being reported in other 34 provinces, regions and cities in China (World Health Organization (2020a, b). Coronavirus disease 2019 (COVID-19): situation report, 72.). The remaining 10,566 cases were reported in 72 countries include Japan, US, 
and Australia, 166 of these were critical (Philippines, Japan, Korea, Italy, France, Iran, Australia, Thailand and the USA). These are only the laboratory-confirmed diagnoses and should not be underestimated (Sohrabi et al. 2020).

\section{COVID-19 pathophysiology}

The cause of COVID-19, SARS-CoV-2 is a betacoronovirus positive single-stranded ribonucleic acid (RNA) virus belongs to Coronavirinae subfamily, part of Coronaviridae family. A structure similar to the typical coronaviruses was shown by sequence analysis of SARS-CoV-2. Its genome is also similar to the strain that caused the SARS outbreak in 2003 (Lu et al. 2019). According to its structure, the SARS-CoV has a well-defined structural composition comprising of 14 binding sites with amino acid residues that directly interact and binds with human angiotensin-converting enzyme and 2 and 8 of these amino acids have been conserved in SARS-CoV-2 (Fehr and Perlman 2015). Until the discovery of SARS-CoV and MERS-CoV, it was thought that coronaviruses cause mild-respiratory diseases. The similarities between SARS-CoV and SARS-CoV-2 can be helpful in order to understand the onset of clinical symptoms of infection (Sohrabi et al. 2020).

\section{Result and discussion}

As no specific drug against SARS-CoV-2 infection has been discovered till date, medical administration mainly emphasizes the significance of care and prevention of transmission of this infection. If a person experiences respiratory stress or shock the priority is to give oxygen to the patient. Vaccine development is an extensive and prolonged procedure and typically takes months to years to develop a licenced vaccine. Standard treatment against the SARS-CoV-2 is still lacking. However, many antivirals, anti-inflammatory and antibiotics are under consideration to review the effect and efficacy combating with SARS-CoV 2 infection (Agostini et al. 2018). Based on the characteristic features of the target, the therapeutics can be divided into two categories. The first one is to modify the immune system by boosting the innate immunity, and the other is to directly target the viral replicating machinery inhibiting the enzymatic processing of the viral genome (Tu et al. 2020). In this article, we have also summarized the combating effects of different antiviral drugs and vaccines against SARS-CoV-2. This includes many drugs but Remdesivir, Favipiravir and Ribavirin are mainly discussed. Remdesivir shows the promising antiviral effects against SARS-CoV-2 by targeting RNA-dependent RNA polymerase (RdRp) of virus. The main mechanism includes the production of premature mRNA by targeting the Viral Exoribonuclease proofreading activity results in termination of RNA transcription (Agostini et al. 2018). Remdesivir is monophosphoramide prodrug nucleotide analogue effective against various virus species including Paramyxoviridae, Orthocoronavirinae, SARS-CoV-1, MERS-CoV and Pneumoviridae (Sheahan et al. 2017).

Although there is less information about drug pharmokinetics, experimental data from rhesus monkey revealed high intracellular penetrance $(>10 \mathrm{mM})$ of $10 \mathrm{mg} / \mathrm{kg}$ dose of Remdesivir intravenously that supports its clinical efficacy in treatment of human SARSCoV 2 (Warren et al. 2016). Early onset of pneumonia was treated with Remdesivir successfully in USA but phase three trials (ClinicalTrials.gov Identifier: NCT04292899 and 
NCT04292730) for moderate and severe condition has been conducted since March 2020 in order to evaluate the efficacy of a drug in severe COVID-19 patients (Holshue et al. 2020).

Favipiravir is RNA-dependent polymerase inhibitor and active known drug for Influenza $\mathrm{A}, \mathrm{B}$ and $\mathrm{C}$ viruses that are resistance to oseltamivir developed by Toyama Chemical (Wang et al. 2019). After converted into active phosphoribosylated, RNA polymerase of many viruses recognized Favipiravir as substrate (Furuta et al. 2017). The efficacy of favipiravir plus interferon- $\alpha$ (ChiCTR2000029600)-based therapy is expected to show synergetic effect on inhibition of viral genome and to amplify the immune response (Tu et al. 2020).

In March 2020, Favipiravir was accepted as antiviral agents in clinical trials in China to check its efficacy against SARS-CoV 2. Although preliminary results of clinical trials show potency of this drug, more detailed analysis is still under consideration. Interferons are immunomodulator showing potency against betacoronavirus of MERS but for SARSCoV-2 patients the effects are still uncertain (Jean et al. 2020).

Ivermectin is an FDA-approved broad-spectrum drug for different types of parasite infestations, also proven as an antiviral agent against HIV, Pseudorabies virus (PRV) and Dengue virus ( Tu et al. 2020). This drug inhibits the IMP $\alpha / \beta 1$ receptors responsible for nuclear import of viral proteins into the host cells. Many studies supported the fact that if given to patient in mild stage of infection it would help to limit the viral load. Results from in vitro experiments demonstrated that control dose of ivermectin can control the viral replication within 24-48 h, but based on pharmacokinetics data further consideration is still needed to ensure the safety profile of this drug (Caly et al. 2020).

Chloroquine is a well-known anti-malarial drug recently referred to as broad-spectrum antiviral against viruses. This drug increases the endosomal $\mathrm{pH}$ thus preventing the fusion of virus to cell (Yan et al. 2013). Invitro study reveals that chloroquine is much promising but due adverse effect on renal and hepatic system it is not prescribed for SARS-CoV-2 (Cortegiani et al. 2020). Another drug hydroxychloroquine is also used to overcome the cytokine storm of the critical stage COVID-19 patient. As compared to chloroquine, the hydroxychloroquine is more potent as to inhibit SARS-CoV-2. In vitro hydroxychloroquine sulphate have much more potency as compared to chloroquine phosphate (Yao et al. 2020). Taiwan CDC professed hydroxychloroquine as potential drug against SARS-CoV 2 since 2020 March but some people that suffered from Glucose-6-phosphatase deficiency, glycogen storage disease type I, patient of retinopathy, pregnant females and hydroxychloroquine allergic persons are contracted to receive this therapy (Gautret et al. 2020). Previously, broad-spectrum antibiotics, antiviral drugs, nebulization and interferons were used. But now, only Remdesivir has shown good results against the virus. Patients were declared clinically recovered after using Remdesivir, and/or chloroquine or interferon beta as combined therapy which targets the $\mathrm{nCoV}-19$ genome and interferes with viral replication (Shereen et al. 2020).

Other antivirals are also being used against infections like ribavirin, penciclovir, ritonavir, favipiravir, AAK1, and arbidrol showed normal outcomes when tested in vitro in clinical trials against infection (Sheahan et al. 2017; Richardson et al. 2020; Wang et al. 2020). Other combinations, such as a combination of antibiotic or antiviral or Chinese medicines were also being tested against nCoV-19 induced infection in mice and humans. Moreover, in Shanghai, doctors used the blood plasma that had been isolated from recovered patients of COVID-19 and injected into infected patients (Shereen et al. 2020). Some other antibiotics and therapies are mentioned in Table 5 with their mode of action. We are facing the worst pandemic globally with no medically prescribed 
Table 5 Summary of mechanism and potential target of some drugs (Jean et al. 2020)

\begin{tabular}{ll}
\hline Drugs & Mechanism of action and targets \\
\hline $\begin{array}{l}\text { Favipiravir } \\
\text { Ribavirin } \\
\text { Remdesivir }\end{array}$ & Inhibition of the RNA-dependent RNA polymerase \\
$\begin{array}{l}\text { Chloroquine } \\
\text { Hydroxychloroquine }\end{array}$ & Inhibition of endosomal acidification (early endosomal pathway) \\
$\begin{array}{l}\text { Interferon-a 2a } \\
\text { Interferon-b 1b }\end{array}$ & Inhibition of viral exocytosis \\
Lopinavir/ritonavir & Inhibition of papain-like protease and 3C-like protease \\
Teicoplanin & Inhibition of lysosomal endopeptidase enzyme (late endosomal pathway) \\
\hline
\end{tabular}

and approved vaccine or therapeutic agent against SARS-CoV-2 to treat the severely ill patients with severe pneumonia. Although the early clinical trials showed the great potency of many drugs, detailed study on full pharmokinetics mode of drugs is still needed to check the potency and safety of drug from severe to moderate SARS-2 (Jean et al. 2020).

Vaccine development is an extensive and critical procedure as it takes time to introduce effective drug that targets the pathogen. Immediately with the discovery and sequencing of novel coronavirus, many companies started working on the vaccine development. Many vaccine candidates successfully passed the phase 1 and entered phase 2 of vaccine development. For many candidates additional testing and trials are still needed in order to commercialize the vaccine. Due to variations in viral replication, transmission and behaviour the development of vaccine is still very challenging (Lurie et al. 2020). The Coalition for Epidemic Preparedness Innovations (CEPI) has been working on many drug candidates and many of them have entered the phase 2 of vaccine development. As of 2 July 2020 the global COVID-19 vaccine R\&D landscape included 158 drug candidates and 23 out of them were disapproved. Remaining 135 molecules are at preclinical trial stage and need to be tested more deeply. mRNA-1273 from Moderna, ChAdOx1 (University of Oxford), Ad5-nCoV from CanSino Biologicals, INO-4800 from Inovio, LV-SMENP-DC and pathogen-specific aAPC from Shenzhen Geno-Immune Medical Institute are the most advanced drug candidates against COVID-19. The latest ongoing clinical trials of different vaccines are given in Table 6.

The more clinical trials and profiling of these drug molecules are still needed to ensure the full potential of a vaccine (Le et al. 2020; Kaur and Gupta 2020). The main strategies of the vaccine are based on protein subunit, live or inactivated attenuated viruses, viral vectors, DNA/RNA vaccine and nanoparticles. The summarized form of these platforms of vaccines is discussed in Table 7 with their advantages and disadvantages.

\section{Major obstacle in research programmes}

Animals have proved to be vital models in order to know the mechanisms of viral pathogenesis to find the entrance to transmission route to design therapeutic strategies. Recently, animals were used in experiments to observe the replication of SARS-CoV. Animals which 

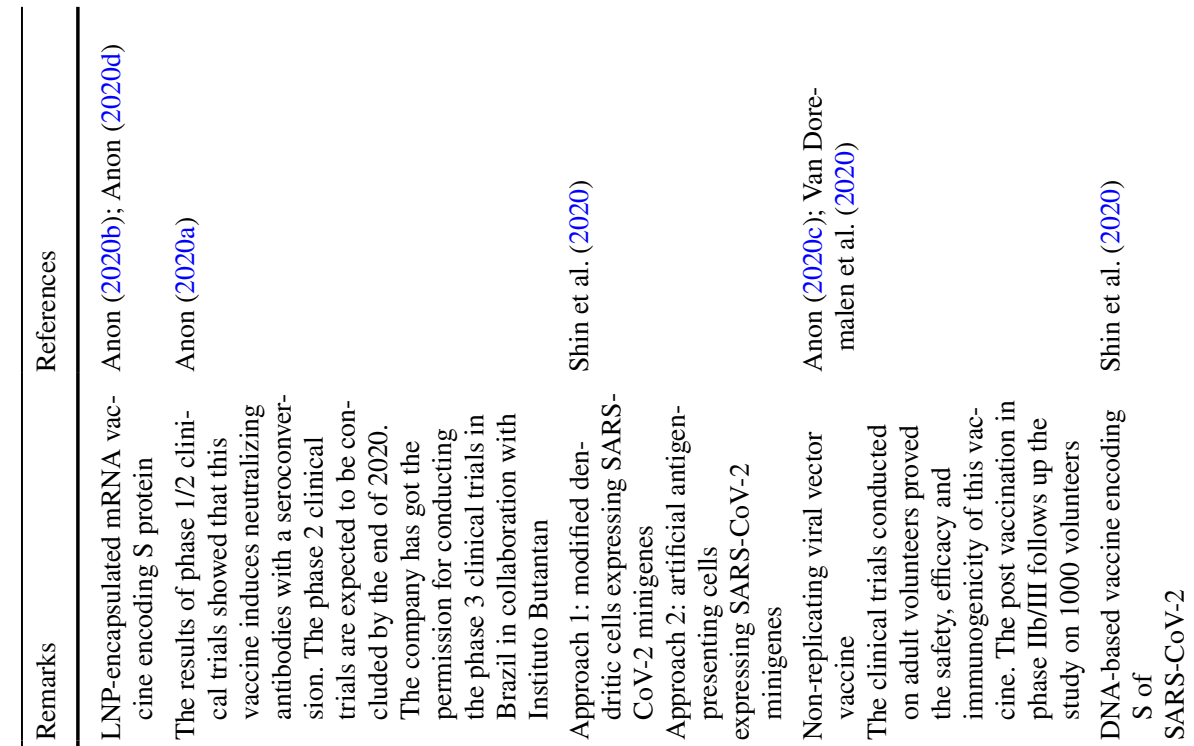

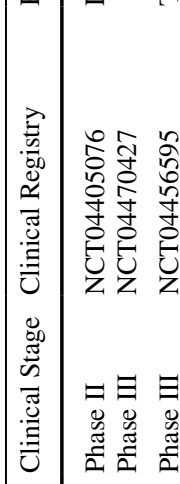

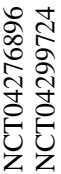

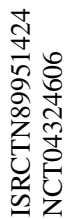

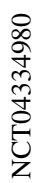

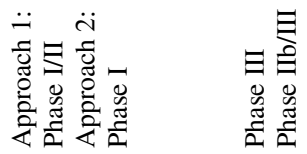

0
$\frac{0}{2}$
$\frac{1}{2}$
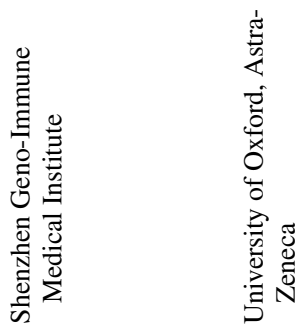

离



है 


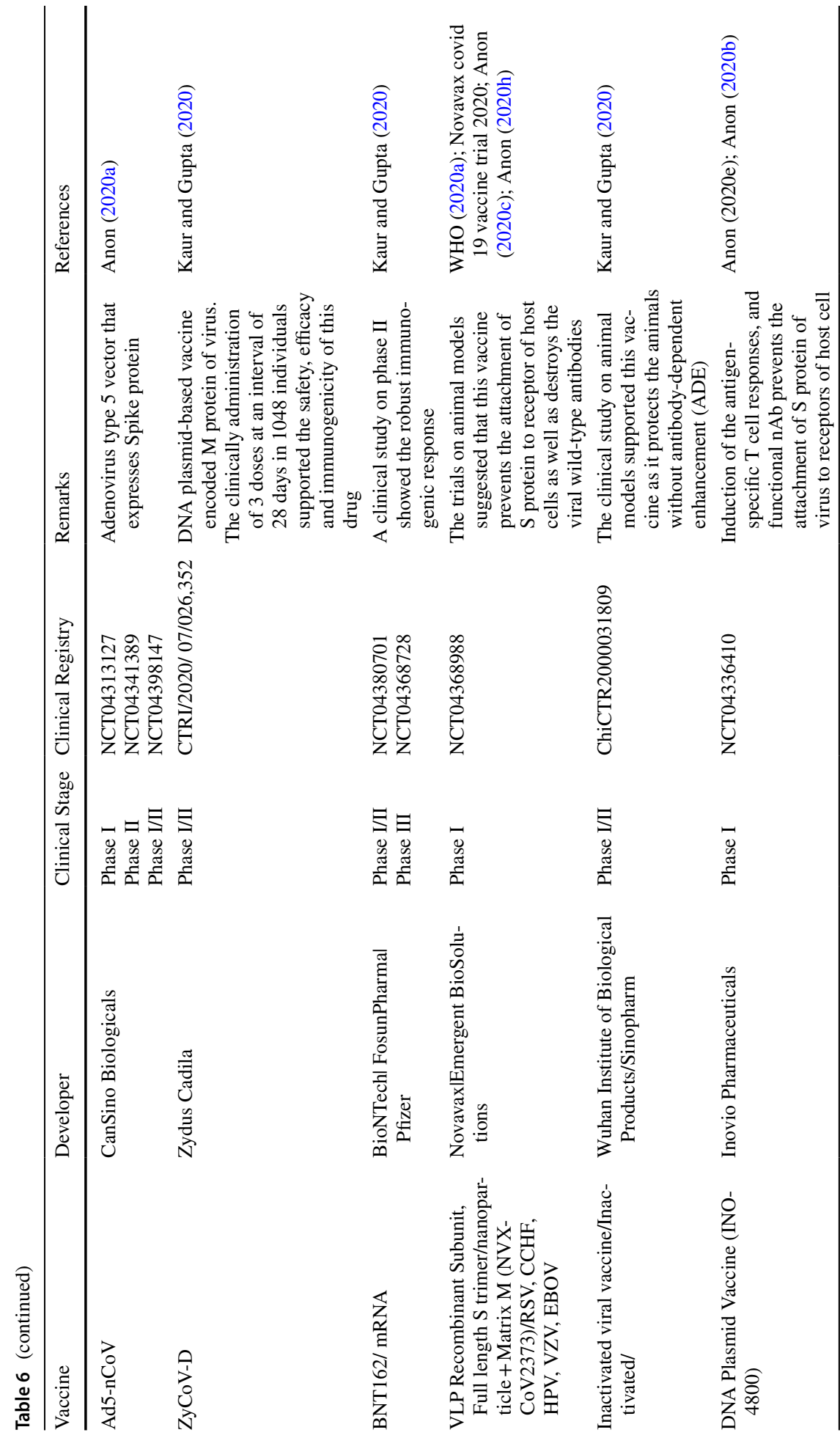




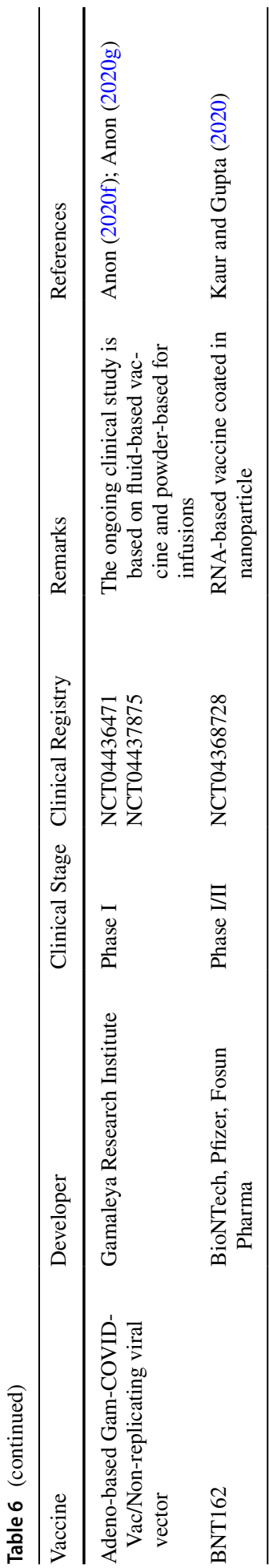

Springer 


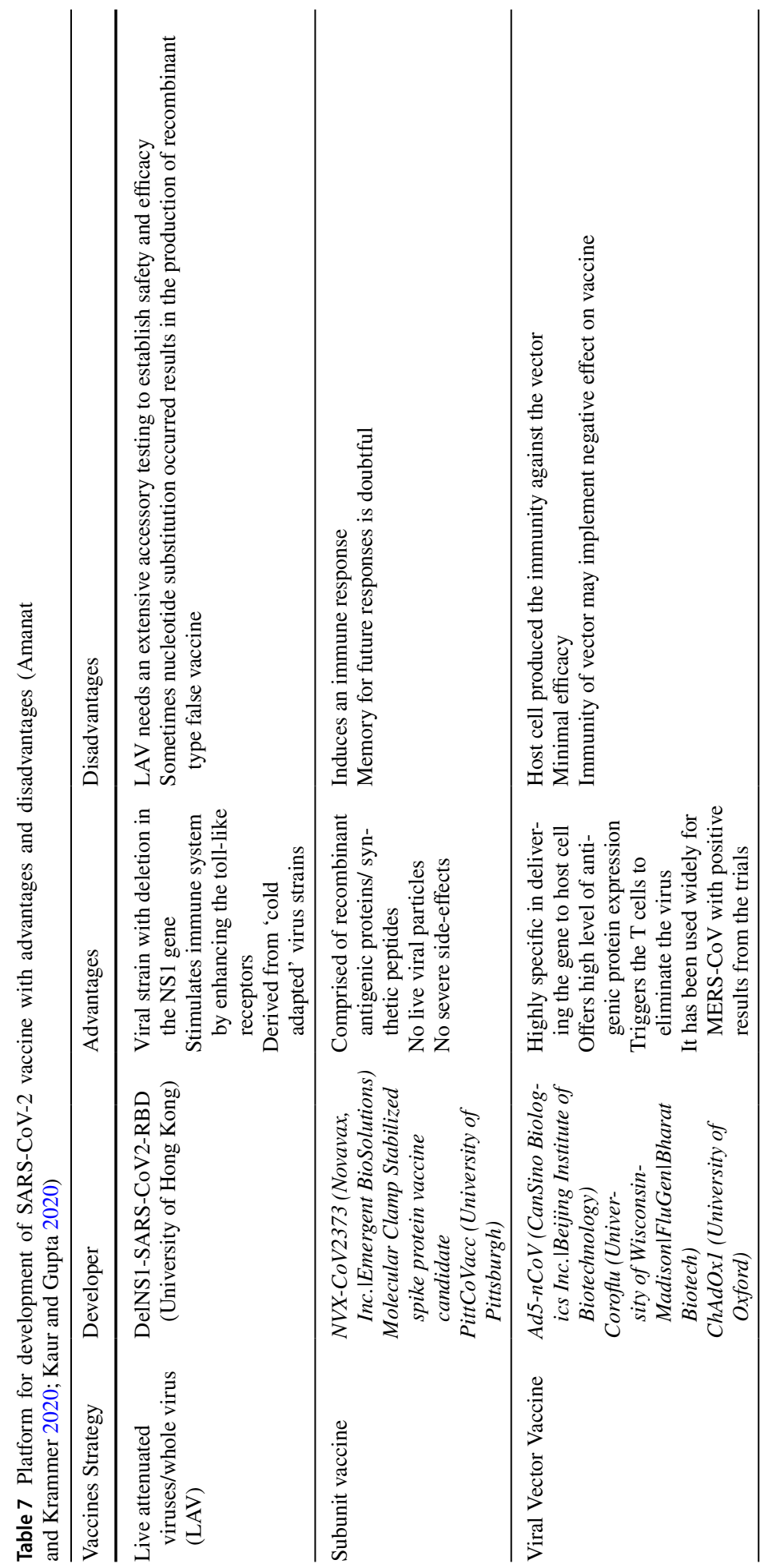




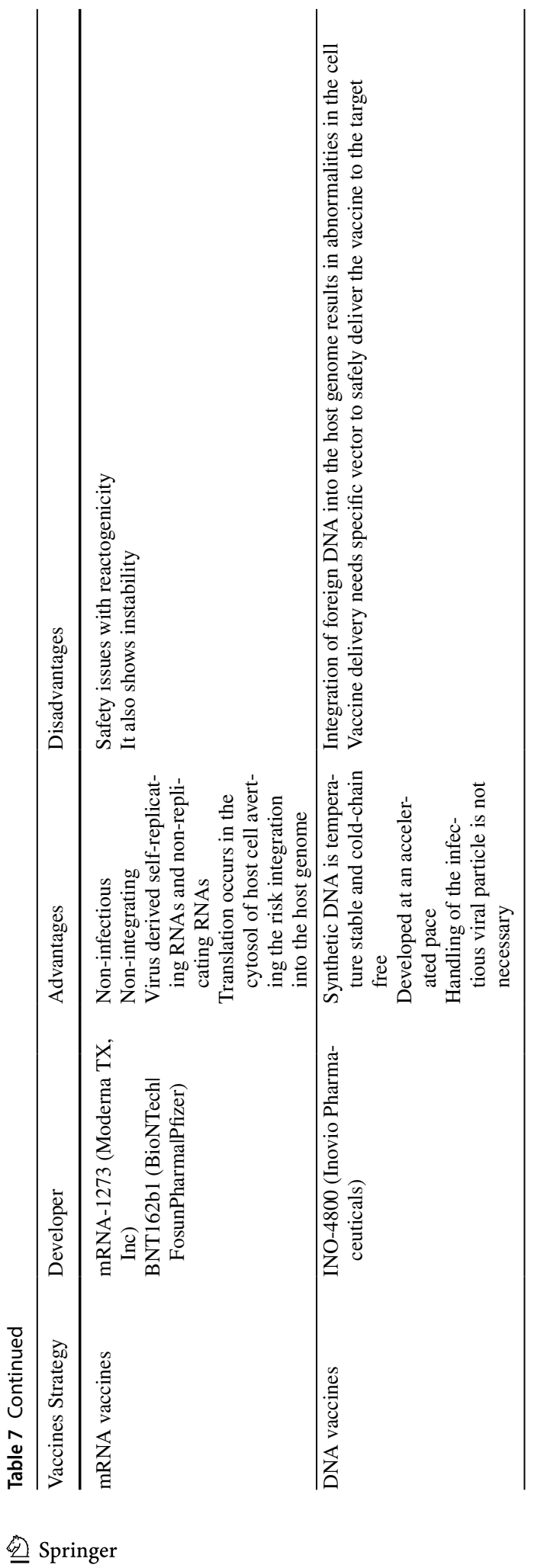


showed the most severe infections were specifically observed (Gretebeck et al. 2015). In comparison to SARS-CoV, no MERS-CoV pathogenesis was found in lower animals. Mice show non-compatibility of the DPP4 receptor that is why they are not prone to the infection by MERS-CoV (Cockrell et al. 2014). The animals that have been used as models for SARS-CoV can be used to study the pathogenesis and transmission route of SARS-CoV-2 because there is more than $80 \%$ similarity between the previously discovered SARS-CoV (Bat-CoV) and nCoV-19 and both viruses recognize the human ACE2 cell receptor. As a conclusion, pathogenicity of novel coronavirus can be studied by utilizing TALEN or CRISPR-mediated genetically modified hamsters or other small animals. Problem is that SARS-CoV causes severe diseases in rats by replicating, where the sequence revealed a mutation at spike glycoprotein (Nagata et al. 2007). Therefore, it is necessary to design a vaccine to target the spike protein of novel coronavirus. COVID-19 induced animals models have been used to explore active sites of viral proteins and to design vaccines to target them.

Similarly, a study investigated the inhibitory role of the drug against SARS-CoV-2 by using artificial intelligence investigation (Richardson et al. 2020). Randomized clinical trials were also conducted using SARS-CoV-2 infected patients. The most effective and important step now is a collaboration between worldwide scientists for designing a suitable model and examining the in vivo mechanisms associated with SARS-CoV-2 pathogenesis (Shereen et al. 2020).

\section{Concluding remarks}

Viruses are dangerous and cause unbearable loss to mankind. Currently similar situation arose the emergence of novel strain of coronavirus not previously identified in past. The pulmonal infection caused by SARS-CoV-2 is highly infectious and declared as a global pandemic by WHO. nCoV-19 is the leading cause of COVID-19 and analysis reveals that sequence of nCoV-like $79 \%$ to betacoronavirus (SARS-CoV). SARS-CoV-2 is tenfold more severe than SARS-CoV-1 and MERS-CoV. Spike protein mediates the entry and adhesion of virus onto host cell receptors. Inhibiting the interaction of virus to ACE2 human receptor is the main target thus to stops the viral entry into the host cell. Previously reported antivirals, antibiotics and interferon from the literature show some effectiveness but only in mild COVID-19 patients. In short SARS-CoV-2 is unique virus from the betacoronavirus family with conserved range of amino acids similar to SARS-CoV $80 \%$ with mutation in RBD domain. More computational and experimental studies are needed in order to find the certain genomic pattern of SARS-CoV-2 in order to find the active site to target the viral genome. Currently ongoing trials provide many promising vaccine candidates include DNA/RNA vaccine, protein subunit vaccine, viral vector vaccine and live viruses vaccine. Many of these candidates have successfully entered the phase II/III of clinical trials but additional toxicological studies are still needed to fully marketize the vaccine. For first wave of SARS-CoV-2, vaccine might be too late, but this pandemic serves as a beacon for scientist community as they will be more prepared from now on to cope up with future CoVs infections. 


\section{Compliance with ethical standards}

Conflict of interest The authors declare that they have no conflict of interest.

Ethical approval This article does not contain any studies with human participants or animals performed by any of the authors.

\section{References}

Agostini, M. L., Andres, E. L., Sims, A. C., Graham, R. L., Sheahan, T. P., Lu, X., et al. (2018). Coronavirus susceptibility to the antiviral remdesivir (GS-5734) is mediated by the viral polymerase and the proofreading exoribonuclease. MBio, 9, 221.

Amanat, F., \& Krammer, F. (2020). SARS-CoV-2 vaccines: Status report. Immunity, 52(4), 583-589.

Anon, (2020a). Sinovac COVID-19 Vaccine collaboration with butantan receives approval from brazilian regulator for phase III Trial. http://www.sinovac.com/. [Online]July 06, 2020. [Cited: August 01, 2020.]. Sinovac Biotech Limited. http ://www.sinovac.com/?optionid=754\&auto_id=907.

Anon, (2020c). COVID-19 Treatment and vaccine tracker. https://airtable.com/. [Online] Milken Institute. https://airtable.com/shrSAi6t5WFwqo3GM/tblEzPQS5fnc0FHYR/viweyymxOAtNvo7yH?block $\mathrm{s}=$ bipZFzhJ7wHPv7x9z .

Anon, (2020f). A study of a candidate COVID-19 vaccine (COV001). https://clinicaltrials.com. gov. [Online]. [Cited: June 8, 2020.]. https://clinicaltrials.gov/ct2/show/NCT04324606?term=vaccine\&cond=covid $-19 \&$ draw $=2$.

Anon, (2020d). Safety and immunogenicity study of 2019-nCoV vaccine (mRNA-1273) for prophylaxis of SARS-CoV-2 Infection (COVID-19). https://clinicaltrials.gov/. [Online]. https://clinicaltrials.gov/ct2/ show/NCT04283461?term $=$ vaccine $\&$ cond $=$ covid $-19 \&$ draw $=2$.

Anon, (2020e). Safety, tolerability and immunogenicity of INO-4800 for COVID-19 in Healthy Volunteers. https://clinicaltrials.gov/. [Online] 2020. 1. https://clinicaltrial.com/s.gov/ct2/show/NCT0433641 0 ?term $=$ inovio \& cond $=$ covid-19\&draw $=2 \&$ rank $=1$.

Anon, (2020f). An Open Study of the Safety, Tolerability and Immunogenicity of the Drug "Gam-COVIDVac" Vaccine Against COVID-19. https://clinicaltrials.gov/. [Online] June 22, 2020. [Cited: June 22, 2020.]. NCT04436471. https://clinicaltrials.gov/ct2/show/NCT04436471?term=vaccine \&cond=covid $-19 \&$ draw $=4$.

Anon, (2020g). An Open Study of the Safety, Tolerability and Immunogenicity of "Gam- COVID-Vac Lyo" Vaccine Against COVID-19. https://clinicaltrials.gov/. [Online] June 22, 2020. [Cited: June 22, 2020.]. NCT04437875. https://clinicaltrials.gov/ct2/show/NCT04437875.

Anon, (2020h). Evaluation of the Safety and Immunogenicity of a SARS-CoV-2 rS (COVID- 19) Nanoparticle Vaccine With/Without Matrix-M Adjuvant. https://clinicaltrials.com/. gov/. [Online] May 27, 2020. [Cited: June 15, 2020.]. https://clinicaltrials.gov/ct2/show/record/NCT04368988.

Ayittey, F. K., Dzuvor, C., Ayittey, M. K., Chiwero, N. B., \& Habib, A. (2020). Updates on Wuhan 2019 novel coronavirus epidemic. Journal of Medical Virology, 92, 403.

Bertram, S., Glowacka, I., Müller, M. A., Lavender, H., Gnirss, K., Nehlmeier, I., et al. (2011). Cleavage and activation of the severe acute respiratory syndrome coronavirus spike protein by human airway trypsin-like protease. Journal of virology, 85, 13363-13372.

Caly, L., Druce, J. D., Catton, M. G., Jans, D. A., \& Wagstaff, K. M. (2020). The FDA-approved drug ivermectin inhibits the replication of SARS-CoV-2 in vitro. Antiviral Research, 178, 104787.

Chan, J. F. W., Kok, K. H., Zhu, Z., Chu, H., To, K. K. W., Yuan, S., \& Yuen, K. Y. (2020). Genomic characterization of the 2019 novel human-pathogenic coronavirus isolated from a patient with atypical pneumonia after visiting Wuhan. Emerging microbes \& infections, 9, 221-236.

Castaño-Rodriguez, C., Honrubia, J. M., Gutiérrez-Álvarez, J., DeDiego, M. L., Nieto-Torres, J. L., Jimenez-Guardeño, J. M., et al. (2018). Role of severe acute respiratory syndrome coronavirus viroporins E, 3a, and 8a in replication and pathogenesis. MBio, 9(3), e02325-17.

Cockrell, A. S., Peck, K. M., Yount, B. L., Agnihothram, S. S., Scobey, T., Curnes, N. R., et al. (2014). Mouse dipeptidyl peptidase 4 is not a functional receptor for Middle East respiratory syndrome coronavirus infection. Journal of Virology, 88, 5195-5199. 
Cortegiani, A., Ingoglia, G., Ippolito, M., Giarratano, A., \& Einav, S. (2020). A systematic review on the efficacy and safety of chloroquine for the treatment of COVID-19. Journal of Citical Care, 57, 279-283.

da Silva, S. J. R., da Silva, C. T. A., Mendes, R. P. G., \& Pena, L. (2020). Role of nonstructural proteins in the pathogenesis of SARS-CoV-2. Journal of Medical Virology, 92(9), 1427-1429.

Das, K. M., Lee, E. Y., Jawder, S. E. A., Enani, M. A., Singh, R., Skakni, L., et al. (2015). Acute Middle East respiratory syndrome coronavirus: Temporal lung changes observed on the chest radiographs of 55 patients. American Journal of Roentgenology, 205, 267-274.

Druce, J., Garcia, K., Tran, T., Papadakis, G., \& Birch, C. (2012). Evaluation of swabs, transport media, and specimen transport conditions for optimal detection of viruses by PCR. Journal of clinical microbiology, 50(3), 1064-1065.

Fehr, A. R., \& Perlman, S. (2015). Coronaviruses: An overview of their replication and pathogenesis. In Coronaviruses (pp. 1-23).

Fuk-Woo, C. J., Shuofeng, Y., \& Kin-Hang, K. (2020). To Kelvin Kai-Wang, Chu Hin, Yang Jin. A familial cluster of pneumonia associated with the 2019 novel coronavirus indicating person-to-person transmission: a study of a family cluster. Lancet, 395, 514-523.

Furuta, Y., Komeno, T., \& Nakamura, T. (2017). Favipiravir (T-705), a broad spectrum inhibitor of viral RNA polymerase. Proceedings of the Japan Academy, Series B, 93, 449-463.

Gautret, P., Lagier, J. C., Parola, P., Meddeb, L., Mailhe, M., Doudier, B., et al. (2020). Hydroxychloroquine and azithromycin as a treatment of COVID-19: Results of an open-label non-randomized clinical trial. International Journal of Antimicrobial Agents, 56, 105949.

Gretebeck, L. M., \& Subbarao, K. (2015). Animal models for SARS and MERS coronaviruses. Current opinion in virology, 13, 123-129.

Hamid, S., Mir, M. Y., \& Rohela, G. K. (2020). Noval coronavirus disease (COVID-19): A pandemic (Epidemiology (p. 100679). New Microbes and New Infections: Pathogenesis and potential therapeutics).

Hoffmann, M., Kleine-Weber, H., Schroeder, S., Krüger, N., Herrler, T., Erichsen, S., et al. (2020). SARS-CoV-2 cell entry depends on ACE2 and TMPRSS2 and is blocked by a clinically proven protease inhibitor. Cell, 181(2), 271-280.

Holshue, M. L., DeBolt, C., Lindquist, S., Lofy, K. H., Wiesman, J., Bruce, H., et al. (2020). First case of 2019 novel coronavirus in the United States. New England Journal of Medicine, 382(10), 929-936.

Huang, C., Wang, Y., Li, X., Ren, L., Zhao, J., Hu, Y., et al. (2020). Clinical features of patients infected with 2019 novel coronavirus in Wuhan, China. The Lancet, 395, 497-506.

Jean, S. S., Lee, P. I., \& Hsueh, P. R. (2020). Treatment options for COVID-19: The reality and challenges. Journal of Microbiology, Immunology and Infection, 53(436), 443.

Ji, W., Wang, W., Zhao, X., Zai, J., \& Li, X. (2020). Cross-species transmission of the newly identified coronavirus 2019-nCoV. Journal of medical virology, 92, 433-440.

Jiang, S., Du, L., \& Shi, Z. (2020a). An emerging coronavirus causing pneumonia outbreak in Wuhan, China: Calling for developing therapeutic and prophylactic strategies. Emerging Microbes \& Infections, 9(1), 275-277.

Jiang, S., Hillyer, C., \& Du, L. (2020b). Neutralizing antibodies against SARS-CoV-2 and other human coronaviruses. Trends in Immunology, 41(5), 355-359.

Jin, Y. H., Cai, L., Cheng, Z. S., Cheng, H., Deng, T., Fan, Y. P., et al. (2020). A rapid advice guideline for the diagnosis and treatment of 2019 novel coronavirus (2019-nCoV) infected pneumonia (standard version). Military Medical Research, 7, 4.

Kakodkar, P., Kaka, N., \& Baig, M. N. (2020). A comprehensive literature review on the clinical presentation, and management of the pandemic coronavirus disease 2019 (COVID-19). Cureus, 12(4), e7560.

Kannan, S., Ali, P. S. S., Sheeza, A., \& Hemalatha, K. (2020). COVID-19 (Novel Coronavirus 2019)recent trends. European review for medical and pharmacological sciences, 24, 2006-2011.

Kaur, S. P., \& Gupta, V. (2020). COVID-19 vaccine: A comprehensive status report. Virus Research, 288, 198114.

Klompas, M., Baker, M. A., \& Rhee, C. (2020). Airborne transmission of SARS-CoV-2: Theoretical considerations and available evidence. Jama, 324(5), 441-442.

Ksiazek, T. G., Erdman, D., Goldsmith, C. S., Zaki, S. R., Peret, T., Emery, S., et al. (2003). A novel coronavirus associated with severe acute respiratory syndrome. New England journal of medicine, 348, 1953-1966.

Lam, T. T. Y., Jia, N., Zhang, Y. W., Shum, M. H. H., Jiang, J. F., Zhu, H. C., et al. (2020). Identifying SARS-CoV-2-related corona viruses in Malayan pangolins. Nature, 583, 282-285. 
Le, T. T., Andreadakis, Z., Kumar, A., Roman, R. G., Tollefsen, S., Saville, M., \& Mayhew, S. (2020). The COVID-19 vaccine development landscape. Nat Rev Drug Discov, 19(5), 305-306.

Li, B., Si, H. R., Zhu, Y., Yang, X. L., Anderson, D. E., Shi, Z. L., et al. (2020a). Discovery of bat coronaviruses through surveillance and probe capture-based next-generation sequencing. Msphere, 5(1), e00807-19.

Li, P., Fu, J. B., Li, K. F., Chen, Y., Wang, H. L., Liu, L. J., et al. (2020b). Transmission of COVID-19 in the terminal stage of incubation period: A familial cluster. International Journal of Infectious Diseases, 6, 452-453.

Lim, Y. X., Ng, Y. L., Tam, J. P., \& Liu, D. X. (2016). Human coronaviruses: A review of virus-host interactions. Diseases, 4(3), 26.

Lu, R., Zhao, X., Li, J., Niu, P., Yang, B., Wu, H., et al. (2020). Genomic characterisation and epidemiology of 2019 novel coronavirus: Implications for virus origins and receptor binding. The Lancet, 395, 565-574.

Lupia, T., Scabini, S., Pinna, S. M., Di Perri, G., De Rosa, F. G., \& Corcione, S. (2020). 2019-novel coronavirus outbreak: A new challenge. Journal of Global Antimicrobial Resistance, 21, 22-27.

Lurie, N., Saville, M., Hatchett, R., \& Halton, J. (2020). Developing Covid-19 vaccines at pandemic speed. New England Journal of Medicine, 382(21), 1969-1973.

Nagata, N., Iwata, N., Hasegawa, H., Fukushi, S., Yokoyama, M., Harashima, A., et al. (2007). Participation of both hostS and virus factors in induction of severe acute respiratory syndrome (SARS) in F344 rats infected with SARS coronavirus. Journal of virology, 81, 1848-1857.

Naji, H. The emerging of the 2019 novel coronavirus 2019-nCoV. Novavax covid 19 vaccine trial, 2020. Clinical trials arena [Online]. https://www.clinicaltrialsarena.com/news/novavax-covid-19-vaccinetrial/ .

Ooi, G. C., Khong, P. L., Müller, N. L., Yiu, W. C., Zhou, L. J., Ho, J. C., et al. (2004). Severe acute respiratory syndrome: Temporal lung changes at thin-section CT in 30 patients. Radiology, 230, 836-844.

Pellett, P. E., Mitra, S., \& Holland, T. C. (2014). Basics of virology. Handbook of clinical neurology, 123, 45-66.

Richardson, P., Griffin, I., Tucker, C., Smith, D., Oechsle, O., Phelan, A., \& Stebbing, J. (2020). Baricitinib as potential treatment for 2019-nCoV acute respiratory disease. Lancet (London, England), 395, e30.

Shang, W., Yang, Y., Rao, Y., \& Rao, X. (2020). The outbreak of SARS-CoV-2 pneumonia calls for viral vaccines. npj Vaccines, 5(1), 1-3.

Sheahan, T. P., Sims, A. C., Graham, R. L., Menachery, V. D., Gralinski, L. E., Case, J. B., et al. (2017). Broad-spectrum antiviral GS-5734 inhibits both epidemic and zoonotic coronaviruses. Science Translational Medicine, 9(396), 3653.

Shereen, M. A., Khan, S., Kazmi, A., Bashir, N., \& Siddique, R. (2020). COVID-19 infection: Origin, transmission, and characteristics of human coronaviruses. Journal of Advanced Research, 24, 91-98.

Shin, M. D., Shukla, S., Chung, Y. H., Beiss, V., Chan, S. K., Ortega-Rivera, O. A., \& Steinmetz, N. F. (2020). COVID-19 vaccine development and a potential nanomaterial path forward. Nature nanotechnology, 15(8), 646-655.

Singh, A., Shaikh, A., Singh, R., \& Singh, A. K. (2020). COVID-19: From bench to bed side. Diabetes \& Metabolic Syndrome: Clinical Research \& Reviews, 14(4), 277-281.

Sohrabi, C., Alsafi, Z., O’Neill, N., Khan, M., Kerwan, A., Al-Jabir, A., et al. (2020). World Health Organization declares global emergency: A review of the 2019 novel coronavirus (COVID19). International Journal of Surgery, 76, 71-76.

Tu, Y. F., Chien, C. S., Yarmishyn, A. A., Lin, Y. Y., Luo, Y. H., Lin, Y. T., \& Wang, M. L. (2020). A review of SARS-CoV-2 and the ongoing clinical trials. International journal of molecular sciences, 21(7), 2657.

ul Qamar, M. T., Rehman, A., Ashfaq, U. A., Awan, M. Q., Fatima, I., Shahid, F., \& Chen, L. L. (2020). Designing of a next generation multiepitope based vaccine (MEV) against SARS-COV-2: Immunoinformatics and in silico approaches. BioRxiv, 15(12), 0244176.

van Boheemen, S., de Graaf, M., Lauber, C., Bestebroer, T. M., Raj, V. S., Zaki, A. M., et al. (2012). Genomic characterization of a newly discovered coronavirus associated with acute respiratory distress syndrome in humans. MBio, 3, e00473-e512.

Van Doremalen, N., Bushmaker, T., Morris, D. H., Holbrook, M. G., Gamble, A., Williamson, B. N., et al. (2020). Aerosol andsurface stability of SARS-CoV-2 as compared with SARS-CoV-1. New England Journal of Medicine, 382(16), 1564-1567. 
Wan, Y., Shang, J., Graham, R., Baric, R. S., \& Li, F. (2020). Receptor recognition by the novel coronavirus from Wuhan: An analysis based on decade-long structural studies of SARS coronavirus. Journal of Virology, 94(7), e00127-20.

Wang, M., Cao, R., Zhang, L., Yang, X., Liu, J., Xu, M., et al. (2020). Remdesivir and chloroquine effectively inhibit the recently emerged novel coronavirus (2019-nCoV) in vitro. Cell research, 30, 269-271.

Wang, Y., Fan, G., Salam, A., Horby, P., Hayden, F. G., Chen, C., et al. (2019). Comparative effectiveness of combined favipiravir and oseltamivir therapy versus oseltamivir monotherapy in critically ill patients with influenza virus infection. The Journal of Infectious Diseases, 221(10), 1688-1698.

Warren, T. K., Jordan, R., Lo, M. K., Ray, A. S., Mackman, R. L., Soloveva, V., et al. (2016). Therapeutic efficacy of the small molecule GS-5734 against Ebola virus in rhesus monkeys. Nature, 531, 381-385.

Wölfel, R., Corman, V. M., Guggemos, W., Seilmaier, M., Zange, S., Müller, M. A., \& Vollmar, P. (2020). 336 Rothe C, Hoelscher M, Bleicker T, Brünink S, Schneider J, Ehmann R, Zwirglmaier K, Drosten C, Wendtner 337 C. Virological assessment of hospitalized patients with COVID2019. Nature, 581(7809), 465-469.

World Health Organization. (2018). Protocol to investigate non-seasonal influenza and other emerging acute respiratory diseases (No. WHO/WHE/IHM/GIP/2018.2). World Health Organization.

World Health Organization. (2020a). Coronavirus disease 2019 (COVID-19): situation report.

World Health Organization. (2020b). Criteria for releasing COVID-19 patients from isolation: scientific brief, 17 June 2020 (No. WHO/2019-nCoV/Sci_Brief/Discharge_From_Isolation/2020.1). World Health Organization.

World Health Organization. (2020c). Laboratory testing for coronavirus disease 2019 (COVID-19) in suspected human cases: interim guidance, 2 March 2020 (No. WHO/COVID-19/laboratory/2020.4). World Health Organization.

Wu, A., Peng, Y., Huang, B., Ding, X., Wang, X., Niu, P., et al. (2020). Genome composition and divergence of the novel coronavirus (2019-nCoV) originating in China. Cell Host \& Microbe, 27(3), 325-328.

Xu, X., Chen, P., Wang, J., Feng, J., Zhou, H., Li, X., et al. (2020). Evolution of the novel coronavirus from the ongoing Wuhan outbreak and modeling of its spike protein for risk of human transmission. Science China Life Sciences, 63, 457-460.

Yan, Y., Zou, Z., Sun, Y., Li, X., Xu, K. F., Wei, Y., et al. (2013). Anti-malaria drug chloroquine is highly effective in treating avian influenza A H5N1 virus infection in an animal model. Cell research, 23, 300-302.

Yao, X., Ye, F., Zhang, M., Cui, C., Huang, B., Niu, P., et al. (2020). In vitro antiviral activity and projection of optimized dosing design of hydroxychloroquine for the treatment of severe acute respiratory syndrome coronavirus 2 (SARS-CoV-2). Clinical Infectious Diseases, 71, 732-739.

Yoshimoto, F. K. (2020). The proteins of severe acute respiratory syndrome Coronavirus-2 (SARS CoV-2 or n-COV19), the cause of COVID-19. The Protein Journal, 39, 198-216.

Yu, F., Du, L., Ojcius, D. M., Pan, C., \& Jiang, S. (2020). Measures for diagnosing and treating infections by a novel coronavirus responsible for a pneumonia outbreak originating in Wuhan. Microbes and infection: China.

Zhang, Z., Wu, Q., \& Zhang, T. (2020). Pangolin homology associated with 2019-nCoV. bioRxiv. https:// doi.org/10.1101/2020.02.19.950253.

Zhao, D., Yao, F., Wang, L., Zheng, L., Gao, Y., Ye, J., et al. (2020). A comparative study on the clinical features of COVID-19 pneumonia to other pneumonias. Clinical Infectious Diseases, 71(15), 756-761.

Zhou, P., Yang, X. L., Wang, X. G., Hu, B., Zhang, L., Zhang, W., et al. (2020). A pneumonia outbreak associated with a new coronavirus of probable bat origin. Nature, 579, 270-273.

Publisher's Note Springer Nature remains neutral with regard to jurisdictional claims in published maps and institutional affiliations. 